\title{
Listeriolysin O Pore-Forming Activity Is Required for ERK1/2 Phosphorylation During Listeria monocytogenes Infection
}

\author{
Changyong Cheng ${ }^{\dagger}$, Jing Sun ${ }^{\dagger}$, Huifei Yu ${ }^{\dagger}$, Tiantian Ma, Chiyu Guan, Huan Zeng, \\ Xian Zhang, Zhongwei Chen and Houhui Song*
}

Key Laboratory of Applied Technology on Green-Eco-Healthy Animal Husbandry of Zhejiang Province, China-Australia Joint Laboratory for Animal Health Big Data Analytics, Zhejiang Provincial Engineering Laboratory for Animal Health Inspection \& Internet Technology, College of Animal Science and Technology \& College of Veterinary Medicine of Zhejiang A\&F University, Hangzhou, China

\section{OPEN ACCESS}

Edited by:

Maria Isabel Colombo, Universidad Nacional de

Cuyo, Argentina

Reviewed by:

Carmen Alvarez-Dominguez, Marqués de Valdecilla Health Research Institute (IDIVAL), Spain

Rebecca Leigh Schmidt, Upper lowa University, United States

*Correspondence: Houhui Song songhh@zafu.edu.cn

†These authors have contributed equally to this work

Specialty section

This article was submitted to Microbial Immunology, a section of the journal

Frontiers in Immunology

Received: 18 December 2019 Accepted: 11 May 2020 Published: 03 June 2020

Citation

Cheng C, Sun J, Yu H, Ma T, Guan C, Zeng $H$, Zhang $X$, Chen $Z$ and Song $H$

(2020) Listeriolysin O Pore-Forming Activity Is Required for ERK1/2

Phosphorylation During Listeria monocytogenes Infection. Front. Immunol. 11:1146. doi: 10.3389/fimmu.2020.01146
Listeriolysin O (LLO) is a cholesterol-dependent cytolysin that mediates escape of L. monocytogenes from phagosomes and enables the bacteria to grow within the host. LLO is a versatile tool allowing Listeria to trigger several cellular responses. In this study, rapid phosphorylation of ERK $1 / 2$ on Caco-2 cells caused by Listeria infection was demonstrated to be highly dependent on LLO activity. The effect could be strongly induced by adding purified recombinant LLO alone and could be inhibited by exogenous cholesterol. Lack of the PEST sequence, known to tightly control cytotoxicity of LLO, did not affect ERK1/2 activation. However, the recombinant non-cytolytic LLOT515AL516A, with mutations in the cholesterol-binding motif, was unable to trigger this response. Recombinant LLON478AV479A, which lacks most of the cytolytic activity, also failed to activate ERK $1 / 2$ phosphorylation, and this effect could be rescued when the protein concentration reached a cytolytic level. Infection with an LLO-deficient mutant $(\Delta h / y)$ or the mutant complementing LLOT515AL516A abrogated the capacity of the bacteria to activate ERK1/2. However, infection with the $\Delta$ hly mutant complementing LLON478AV479A, which retained partial pore-forming ability and could grow intracellularly, was capable of triggering ERK1/2 phosphorylation. Collectively, these data suggest that ERK1/2 activation by L. monocytogenes depends on the permeabilization activity of LLO and more importantly correlates with the cholesterol-binding motif of LLO.

Keywords: Listeria monocytogenes, listeriolysin O (LLO), pore-forming activity, ERK1/2 phosphorylation, cholesterol-binding motif

\section{INTRODUCTION}

Listeria monocytogenes, a facultative intracellular pathogen that has the capacity to actively invade and multiply within mammalian cells, is the causative agent of listeriosis, which affects immunocompromised individuals, as well as pregnant women and elderly people $(1,2)$. L. monocytogenes can thrive in a variety of environments and has the remarkable ability to cross various host barriers. Owing to its environmental adaptability and unique intracellular lifestyle, this bacterium has come to the forefront as a model system to study bacterial infection biology and host-pathogen interactions (3). Listeriolysin O (LLO) is a key determinant of L. monocytogenes 
pathogenesis, mediating vacuole degradation and escape. LLO is a member of the cholesterol-dependent cytolysins (CDCs), which is the largest family of bacterial pore-forming toxins (PFTs) produced by many pathogenic Gram-positive bacteria (4-6). LLO is a phagosome-specific cytolysin that forms pores in host membranes and is continuously expressed throughout the intracellular lifecycle of L. monocytogenes. Uncontrolled expression of LLO could lead to perforation of organelles and the host plasma membrane from the inside of the cell, causing cell death and destruction of the intracellular niche of L. monocytogenes, and thereby exposing the bacteria to the host immune system $(5,7,8)$. Therefore, L. monocytogenes tightly controls synthesis and activity of LLO to disrupt vacuolar membranes without killing host cells. It is well-established that L. monocytogenes mutants with increased LLO expression or activity efficiently escape from vacuoles but are less virulent because they over-toxic to host cells, thereby destroying their intracellular niche (9). LLO is the only cytolysin of the PFTs that is made by an intracellular pathogen. As a result, LLO has an incontrovertible acidic $\mathrm{pH}$ optimum and can be denatured at neutral $\mathrm{pH}$ to restrict its cytolytic activity (10). Moreover, the PEST-like sequence of LLO near its $\mathrm{N}$-terminus that reduces the intracellular toxicity of this cytolysin is necessary for $L$. monocytogenes to better survive intracellularly following escape from phagocytic vacuoles $(6,11)$.

Exposure to PFTs leads to plasma membrane damage and cell death, and the LLO-induced pore-forming effect that results in rapid $\mathrm{Ca}^{2+}$ influx and $\mathrm{K}^{+}$efflux can also trigger different categories of cellular responses during bacterial infection (12). These responses include modulation of mitogen-activated protein kinase (MAPK) (13-15), SUMOylation dysregulation (16), endoplasmic reticulum stress (17), mitochondrial fragmentation (18), inflammasome activation (19) and histone modification (20). The MAPK signaling transduction pathway, one of the most important regulatory mechanisms in eukaryotic cells and essential for the host immune response, can be manipulated by bacterial pathogens to their advantage $(21,22)$. Activated MAPK translocates to the nucleus to activate, by phosphorylation, proteins required for transcription of genes, including proinflammatory signaling molecules. Three different mammalian MAPK cascades have been described to date, and are named according to their MAPK components: extracellular signal-regulated kinase 1 and 2 (ERK1/2), as well as c-Jun $\mathrm{N}$-terminal kinase (JNK) and p38, with all three activated by hierarchical phosphorylation (23).

Given the importance of MAPK signaling pathways in regulating immune responses, it is not surprising that many bacterial pathogens have developed mechanisms to directly or indirectly modulate MAPK activation or inhibition (24). These pathogens often use effector proteins to manipulate MAPK pathways and allow the bacteria to establish infection within the host (21). Employing a model of the bloodcerebrospinal fluid barrier based on human choroid plexus epithelial papilloma (HIBCPP) cells, a previous study showed that infection with L. monocytogenes triggers activation of ERK1/2 and p38 signaling, and such cellular response is required for L. monocytogenes infection $(22,25)$. Modulation of MAPK pathway signaling by LLO during L. monocytogenes infection has been described in various host cell lines. Infection of epithelial cells by L. monocytogenes could activate phosphorylation of MAPK kinases through the action of LLO, and this was essential for invasion of Listeria into host cells (13-15). On the contrary, LLO also contributes to inhibition of MAPK signaling pathway activation and infection-associated abortion by dephosphorylation of MAPK family proteins during L. monocytogenes infection in trophoblast giant cells (26). Unlike other CDCs, LLO displays unique characteristics that limit its cytotoxicity. However, correlation between the pore-forming activity of LLO and the ability to manipulate MAPK pathways is unclear, and the detailed mechanistic contribution of LLO in MAPK pathway signaling needs further study.

In the present study, the roles of the critical domains of LLO that determine pore-forming activity involved in the phosphorylation of ERK1/2 MAP kinases during L. monocytogenes infection of human intestinal epithelial cells were investigated. Our data suggest that permeabilization activity on host cell membranes by the amino acid pair Thr515-Leu516 of LLO is critical to activate L. monocytogenes infection-induced ERK1/2 phosphorylation. Furthermore, adding the purified LLO alone at a very low cytotoxic concentration is sufficient to induce this cellular response, while mutations in the cholesterol-binding motif render LLO incapable of activating ERK1/2 signaling.

\section{MATERIALS AND METHODS}

\section{Bacterial Strains and Culture Conditions}

The strains L. monocytogenes EGD-e, $\Delta h l y$, C $\Delta h l y$, $\mathrm{C} \Delta h l y_{\mathrm{N} 478 \mathrm{AV} 479 \mathrm{~A}}$, and $\mathrm{C} \Delta h l y_{\mathrm{T} 515 \mathrm{AL} 479 \mathrm{~A}}$, and E. coli $\mathrm{DH} 5 \alpha$ and Rosetta were used in this study. The gene deletion mutant $\Delta h l y$ was generated from parental strain EGD-e using the homologous recombination method (27). All complemented strains were derived from $\Delta h l y$. Mutants of the $h l y$ gene were cloned into the integration plasmid pIMK2 driven by the hly promoter and then introduced into $\Delta h l y$ background. All resulting mutations were confirmed by sequencing. All strains of Listeria were cultured in brain heart infusion (BHI) broth (Thermo Fisher Scientific, Waltham, USA) at $37^{\circ} \mathrm{C}$ with shaking or on BHI broth containing $1.5 \%$ agar (Sangon, Shanghai, China). E. coli strains were grown at $37^{\circ} \mathrm{C}$ in Luria-Bertani broth (LB) (Thermo Fisher Scientific) or on LB broth containing $1.5 \%$ agar.

\section{Overexpression and Purification of His-Tagged LLO Proteins From E. coli}

Recombinant LLO proteins used in this study were expressed as fusion proteins to the N-terminal His-tag using pET30a $(+)$ as the expression vector (4). Briefly, the hly gene from EGDe genome was amplified and inserted into the pET30a $(+)$ vector, and finally transformed into Rosetta competent cells. $E$. coli cells harboring the recombinant plasmids were grown in $500 \mathrm{~mL}$ LB medium supplemented with $50 \mu \mathrm{g} / \mathrm{mL}$ kanamycin at $37^{\circ} \mathrm{C}$ until the cultures reached $0.8-1.0$ at $\mathrm{OD}_{600 \mathrm{~nm}}$. Isopropyl $\beta$-D-1-thiogalactopyranoside (IPTG) was then added to a final concentration of $0.4 \mathrm{mM}$ to induce expression of the 
recombinant proteins for additional $4 \mathrm{~h}$. The His-tagged fusion proteins were purified using the nickel-chelated affinity column chromatography. For generation of the mutants $\left(\mathrm{LLO}_{\mathrm{N} 478 \mathrm{AV} 479 \mathrm{~A}}\right.$ and $\mathrm{LLO}_{\mathrm{T} \text { 515AL516A }}$ ), the QuikChange Site-Directed Mutagenesis kit (Agilent Technologies, Palo Alto, USA) was used according to the instructions. All mutant constructs were sequenced to ensure that only the desired single mutations had been incorporated correctly. These LLO mutant proteins were expressed and purified as described above.

\section{LLO-Mediated Hemolytic Assay}

Measurement of LLO-associated hemolytic activity was performed as previously described $(4,28)$. Briefly, strains of L. monocytogenes were grown for $12 \mathrm{~h}$ with shaking in $\mathrm{BHI}$ broth at $37^{\circ} \mathrm{C}$. All cultures were adjusted to an $\mathrm{OD}_{600}$ of 1.0 before supernatant protein samples were collected. Hemolytic activity was measured based on lysis of sheep red blood cells (SRBCs) by secreted LLO from culture supernatants. Specifically, culture supernatant $(50 \mu \mathrm{L})$ was diluted in hemolysis buffer $(10 \mathrm{mM}$ PBS, pH 5.5 or $7.4,150 \mathrm{mM} \mathrm{NaCl}, 1 \mathrm{mM}$ DTT) in a final volume of $50 \mu \mathrm{L}$, and equilibrated to $37^{\circ} \mathrm{C}$ for $10 \mathrm{~min}$. Next, $100 \mu \mathrm{L}$ PBS-washed intact SRBCs (5\%) were added to each sample and incubated at $37^{\circ} \mathrm{C}$ for $30 \mathrm{~min}$. Samples were centrifuged and supernatants analyzed for hemoglobin absorption at $550 \mathrm{~nm}$. For hemolysis determination of recombinant proteins, purified LLO or mutant LLO protein (LLO $_{\text {N478AV479A }}$ or $\mathrm{LLO}_{\mathrm{T} 515 \mathrm{AL} 516 \mathrm{~A}}$ ) expressed in $E$. coli was serially diluted in hemolysis buffer, then mixed with an equal volume of 5\% SRBC and the hemolytic activity was determined as described above. The values corresponding to the reciprocal of the dilution of culture supernatant required to lyse 5\% SRBCs were used to compare the hemolytic activities in the different supernatants. Erythrocytes incubated with $1 \%$ Triton X-100 or PBS served to determine the maximum (100\%) and minimum (0\%) hemolytic activity, respectively.

\section{Immunoblotting}

Cytoplasmic cell extracts were separated by SDS-PAGE and transferred to polyvinylidene difluoride (PVDF) membranes for western blotting. Membranes were incubated with p44/42 MAPK (ERK1/2) rabbit monoclonal antibody (Cell Signaling Technology, Danvers, USA), Phospho-p44/42 MAPK (ERK1/2) rabbit monoclonal antibody (Cell Signaling Technology), or anti $\beta$-actin antibody (Sigma-Aldrich, St. Louis, USA) at $4^{\circ} \mathrm{C}$ overnight, as appropriate. After washing with Tris-buffered saline (TBS) containing $0.02 \%(\mathrm{v} / \mathrm{v})$ Tween 20 , membranes were incubated with horseradish peroxidase-conjugated secondary antibody (Sigma-Aldrich) at $37^{\circ} \mathrm{C}$ for $1 \mathrm{~h}$. Immunoreactions were then visualized using the enhanced chemiluminescence detection system (UVP Inc., Upland, USA).

\section{Cell Fractionation and Protein Localization of LLO}

Western blotting was employed to analyze the changes in expression of LLO as previously described (29). Overnight cultures of L. monocytogenes were diluted into $200 \mathrm{~mL}$ fresh BHI broth, and bacteria were grown to stationary phase. For isolation of secreted proteins, bacterial cells were pelleted by centrifugation at $13,000 \mathrm{~g}$ for $20 \mathrm{~min}$ at $4^{\circ} \mathrm{C}$, and the resulting supernatant was collected and passed through a $0.22 \mu \mathrm{m}$ polyethersulfone membrane filter (Thermo Fisher Scientific). Trichloroacetic acid (TCA) was added to the supernatant to a final concentration of $10 \%$. Proteins were TCA-precipitated on ice overnight and washed with ice-cold acetone. The washed precipitates were resuspended in SDS-PAGE sample buffer (5\% SDS, 10\% glycerol, and $50 \mathrm{mM}$ Tris- $\mathrm{HCl}, \mathrm{pH} 6.8$ ), boiled for $6 \mathrm{~min}$ and stored at $-20^{\circ} \mathrm{C}$ before electrophoresis. For isolation of total cell proteins, bacterial pellets were resuspended in $1 \mathrm{~mL}$ extraction solution (2\% Triton X-100, 1\% SDS, $100 \mathrm{mM} \mathrm{NaCl}, 10 \mathrm{mM}$ Tris-HCl, $1 \mathrm{mM}$ EDTA, $\mathrm{pH} 8.0$ ). One gram of glass beads (G8772, SigmaAldrich) was added and samples were lysed using a Precelly 24 homogenizer (Bertin, Provence, France) at 6,000 rpm for $30 \mathrm{~s}$ with intermittent cooling for $30 \mathrm{~s}$ (three cycles in total). Samples were then centrifuged at $12,000 \mathrm{rpm}$ for $15 \mathrm{~min}$, and the supernatant was retained as the whole cell extract. Protein samples were separated through a $12 \%$ SDS-PAGE gel and were immunoblotted with $\alpha$-LLO, or $\alpha$-GAPDH antibodies. GAPDH was used as an internal control.

\section{Propidium lodide Assay of Membrane Integrity}

Caco- 2 cells were plated at $1.0 \times 10^{6}$ cells per well in 12 -well tissue culture plates with glass coverslips and were cultured for $12 \mathrm{~h}$. Cells were infected with bacteria [multiplicity of infection (MOI) 10:1] or treated with various concentrations of LLO (or its variants) diluted in serum-free DMEM for $3 \mathrm{~h}$ or $30 \mathrm{~min}$ at $37^{\circ} \mathrm{C}$, respectively. Cells were then washed with $\mathrm{PBS}$ and incubated with $0.4 \mathrm{mg} / \mathrm{ml}$ propidium iodide (Sigma-Aldrich) at $37^{\circ} \mathrm{C}$ for $10 \mathrm{~min}$ before fixing with $4 \%$ paraformaldehyde and counterstaining with DAPI (4',6-diamidino-2-phenylindole) (Thermo Fisher Scientific). Cells were imaged on a ZEISS LSM510 confocal microscope equipped with a $\times 10$ objective.

\section{Proliferation in RAW264.7 Macrophages}

Stationary L. monocytogenes were washed and re-suspended in $10 \mathrm{mM}$ PBS (pH 7.4). Monolayers of RAW264.7 cells cultured in DMEM (Thermo Fisher Scientific) containing 10\% FBS (Hyclone, Chicago, USA) were infected with bacteria at an MOI of 0.05 . After incubation for $30 \mathrm{~min}$, infected cells were washed twice with PBS and incubated in DMEM containing $50 \mu \mathrm{g} / \mathrm{mL}$ gentamicin for additional $30 \mathrm{~min}$ to kill extracellular bacteria. At $2,6,12$, or $18 \mathrm{~h}$ post infection, cells were lysed by adding $1 \mathrm{~mL}$ ice-cold sterile distilled water and lysates were diluted 10-fold for enumeration of viable bacteria on BHI agar plates.

\section{Plaque Assay in L929 Fibroblast Cells}

The plaque assay was carried out by conventional methods (4). Briefly, murine L929 fibroblast cell monolayers were maintained in high-glucose DMEM containing FBS (Hyclone) and $2 \mathrm{mM}$ L-glutamine. Cells were seeded at $1 \times 10^{6}$ cells per well in 6-well plates and infected with $L$. monocytogenes at an MOI of $1: 50$ for $1 \mathrm{~h}$ at $37^{\circ} \mathrm{C}$ and $5 \% \mathrm{CO}_{2}$. Extracellular bacteria were killed with $50 \mu \mathrm{g} / \mathrm{mL}$ gentamicin for $60 \mathrm{~min}$, and the cells washed three times with $10 \mathrm{mM}$ PBS ( $\mathrm{pH} 7.4)$ and then 
overlaid with $3 \mathrm{~mL}$ medium plus $0.7 \%$ agarose and $10 \mu \mathrm{g} / \mathrm{mL}$ gentamicin. Following a 72 -h incubation at $37^{\circ} \mathrm{C}$, cells were fixed with paraformaldehyde (4\% in PBS for $20 \mathrm{~min}$ ) and stained with crystal violet. Plaque diameter for each bacterial strain was measured using Adobe Photoshop software. The plaque size of wild-type strain EGD-e was set as $100 \%$ and data are shown as mean \pm SD.

\section{Cytotoxicity Detection}

Cytotoxicity was detected based on lactate dehydrogenase (LDH) release from J774 macrophages following bacterial infection and using the CytoTox 96 non-radioactive cytotoxicity assay kit according to the manufacturer's instructions (Promega, Wisconsin, USA), as previously described $(4,30)$. Overnight cultures of L. monocytogenes were deposited onto J774 cells at a MOI of 10 and incubated for $30 \mathrm{~min}$ at $37^{\circ} \mathrm{C}$ and $5 \%$ $\mathrm{CO}_{2}$. Culture medium with or without $50 \mu \mathrm{g} / \mathrm{mL}$ gentamicin was then added. To determine maximum LDH release, 100 $\mu \mathrm{L}$ lysis buffer was added to triplicate-infected wells $45 \mathrm{~min}$ prior to $\mathrm{LDH}$ measurement. At the indicated infection times $(2,4$, and $6 \mathrm{~h})$, cells were centrifuged at $250 \mathrm{~g}$ for $5 \mathrm{~min}$, and the supernatant was removed and used for the LDH assay. The supernatant was incubated for $30 \mathrm{~min}$ with $50 \mu \mathrm{L}$ substrate mix prior to the addition of $50 \mu \mathrm{L}$ stop solution. Absorption of the samples at $490 \mathrm{~nm}$ was then measured using a Synergy H1 micro-plate reader (BioTek, Winooski, USA). The experimental design included 3-wells containing only DMEM to account for background absorption, as well as 3-wells containing uninfected J774 cells to measure spontaneous LDH release. After background correction, the percent cytotoxicity was calculated as follows: cytotoxicity $\%=[($ experimental $\mathrm{LDH}$ release-spontaneous $\mathrm{LDH}$ release)/(maximum $\mathrm{LDH}$ releasespontaneous $\mathrm{LDH}$ release)] $\times 100$.

\section{Virulence in the Mouse Model}

Wild-type and mutant strains of L. monocytogenes were tested for their ability to be recovered from mouse organs (livers and spleens). Briefly, ICR mice (female, 18-22 g) (eight mice per group) were inoculated intraperitoneally with $10^{6} \mathrm{CFU}$ of each strain. At 24 and $48 \mathrm{~h}$ post-infection, mice were sacrificed, and livers and spleens were removed and individually homogenized in $10 \mathrm{mM}$ PBS ( $\mathrm{pH}$ 7.4). Surviving bacteria were enumerated by plating serial dilutions of homogenates on $\mathrm{BHI}$ agar plates.

\section{Statistical Analysis}

All experiments were repeated at least three times. Data were analyzed using the two-tailed homoscedastic Student's $t$-test. $P$-values $<0.05$ were considered statistically significant.

\section{Ethics Statement}

All animal care and use protocols were performed in accordance with the Regulations for the Administration of Affairs Concerning Experimental Animals approved by the State Council of People's Republic of China. The protocol was approved by the Institutional Animal Care and Use Committee of Science Technology Department of Zhejiang Province (Permit Number: SYXK-2018-0010). All the L. monocytogenes-involved experiments in our study were conducted at Biosafety Level 2 (BSL-2) laboratory.

\section{RESULTS}

\section{LLO Is Critical for Induction of ERK1/2 Phosphorylation in Response to L. monocytogenes Infection in Caco-2 Cells}

Since the MAPK ERK1/2 pathway is involved in infection of host cells by bacterial pathogens, phosphorylation of ERK1/2 in Caco-2 cells after infection with L. monocytogenes was analyzed by immunoblotting and compared with the uninfected control. Phosphorylated ERK1/2 (p-ERK1/2) was significantly activated by bacterial infection in a time-dependent manner (Figure 1A). However, the total amounts of ERK1/2 protein did not significantly change during infection with $L$. monocytogenes. The mechanism by which LLO activates ERK1/2 in host cells was then investigated. A mutant lacking the hly gene was unable to induce ERK1/2 phosphorylation during infection, and this compromised ability could be partially restored by complementation of a functional LLO into the $h l y$-deleted mutant $(\Delta h l y)$ (Figure 1B). Moreover, Caco-2 cells incubated with as little as $\sim 1.5$ hemolytic units $(5 \mathrm{nM}$, according to the hemolytic activity assay in this study) of the purified LLO showed a more rapid phosphorylated ERK1/2 activation starting at $5 \mathrm{~min}$ incubation with a maximum at 15 and $30 \mathrm{~min}$, and decreasing as the incubation time continued (Figure 1C). The activation effect of LLO on ERK1/2 phosphorylation was concentrationdependent, and a very low concentration of $0.5 \mathrm{nM}$ was sufficient to activate ERK1/2 phosphorylation (Figure 1D). Taken together, these results established a critical role for LLO in the activation of p-ERK1/2 during L. monocytogenes infection of epithelial cells.

\section{Pore-Forming Activity of LLO Is Required for LLO-Mediated ERK1/2 Phosphorylation}

To explore the correlation between pore-forming activity of LLO and its ability to activate ERK1/2 phosphorylation, two double-amino-acid mutations were introduced into the wild-type LLO. The resulting LLO mutant proteins (LLO ${ }_{\mathrm{T} 515 \mathrm{AL} 516 \mathrm{~A}}$ and $\mathrm{LLO}_{\mathrm{N} 478 \mathrm{AV} 479 \mathrm{~A}}$ ) were purified (Figure 2A) and used to investigate the effect of the mutations on ERK1/2 phosphorylation. The hemolysis assay showed that recombinant LLO $_{\text {T515AL516A }}$ with mutations in the cholesterol-binding motif completely lost its ability to lyse erythrocytes even at high concentrations (Figure 2B). We previously showed that Asn478 and Val479 are key residues required for LLO hemolytic activity (4). In agreement with this, recombinant LLO $_{\text {N478AV479A }}$ was completely impaired in cytolytic ability within a certain concentration range; however this could be fully restored by increasing the protein concentration to $\sim 20 \mathrm{nM}$ (Figure 2B). The ability of recombinant LLO and its variants to induce permeabilization of Caco-2 cells was further examined using propidium iodide (PI), a membrane-impermeable dye for nucleic acids. Consistently, recombinant wild-type LLO at a concentration of $5 \mathrm{nM}$ was sufficient to cause obvious cell 
A
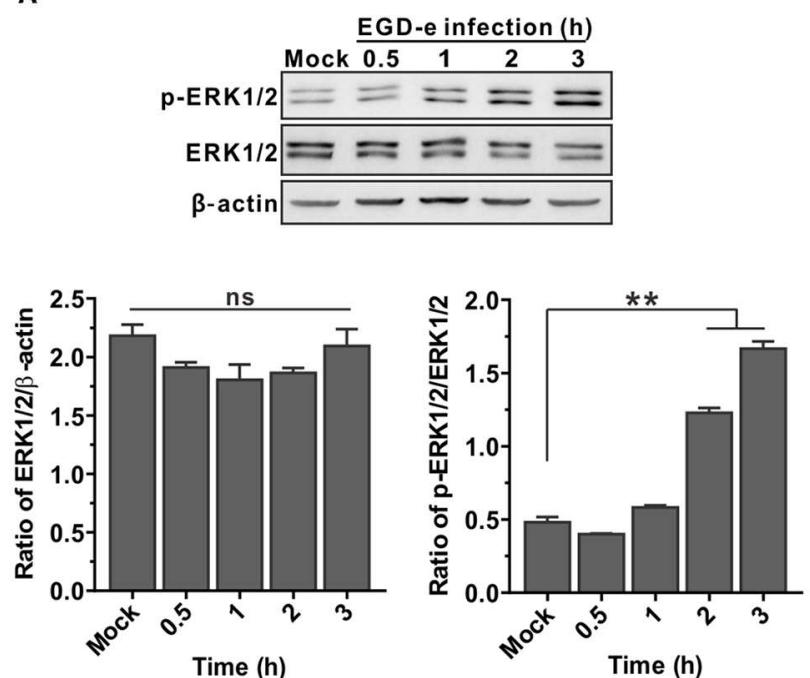

C
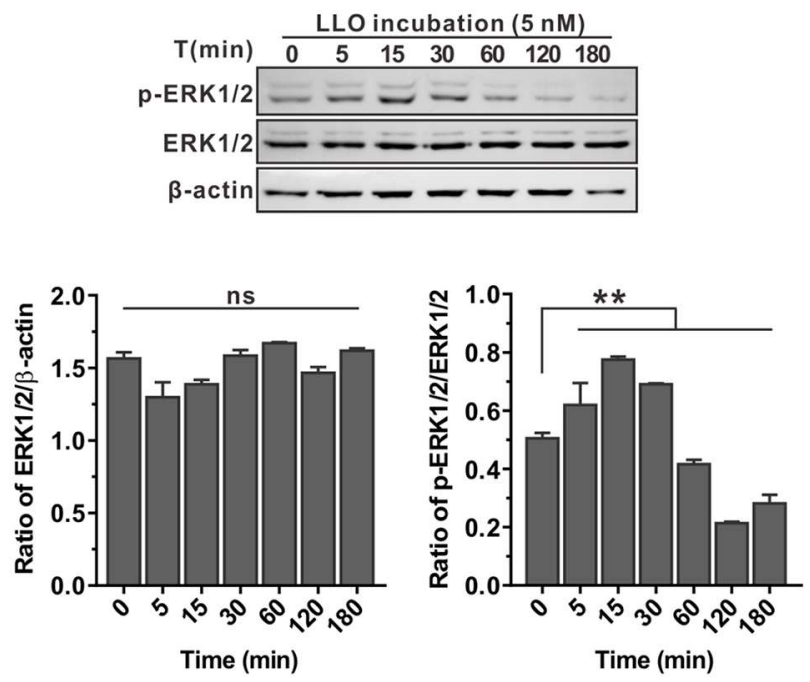

B
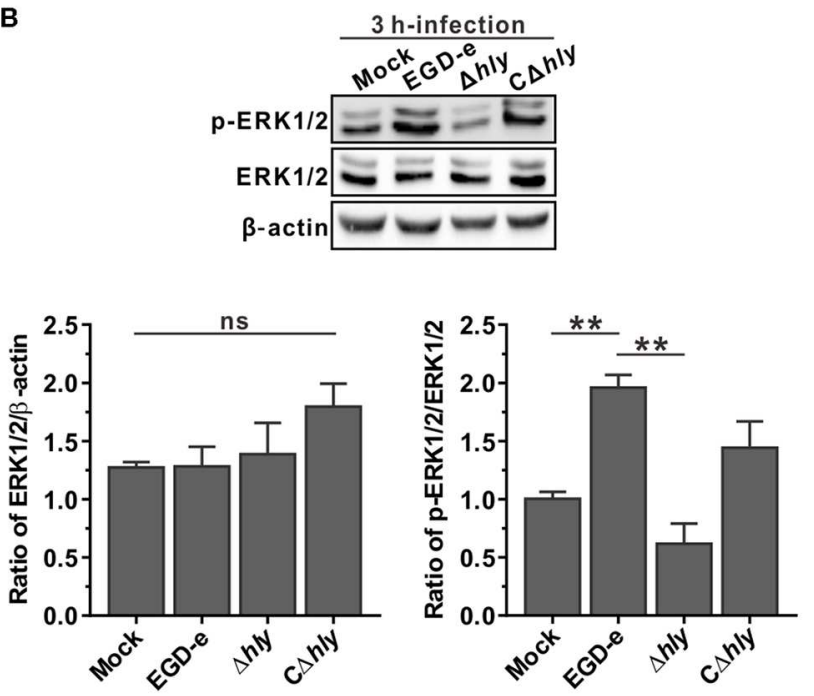

D

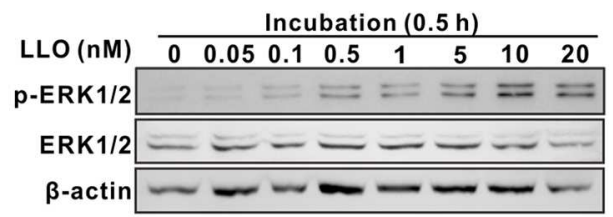
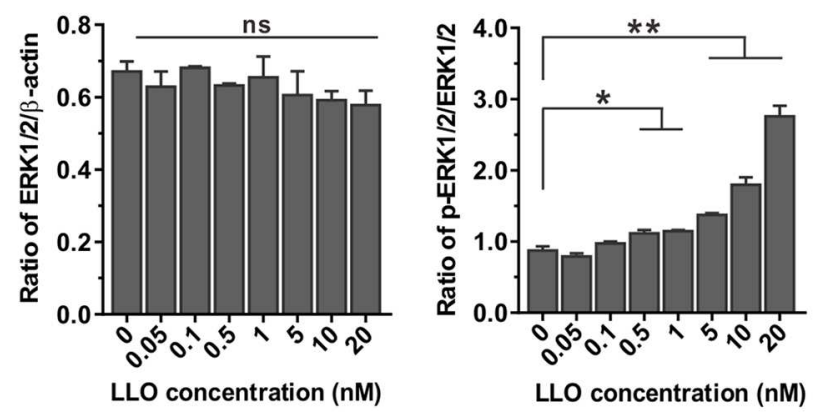

FIGURE 1 | ERK1/2 phosphorylation triggered by L. monocytogenes infection in Caco-2 cells is LLO-dependent. (A,B) Expression of MAP kinases ERK1 and ERK2 in Caco-2 human epithelial cells infected with L. monocytogenes wild-type EGD-e (A) or the hly deletion and complemented mutants (B) for the indicated time points. Expression of the indicated proteins was detected by immunoblotting, with $\beta$-actin used as an internal control. Phosphorylated ERK1/2 is designated $p$-ERK1/2. (C,D) Expression of ERK1/2 in Caco-2 cells treated with purified recombinant LLO at different time points (C) and with various concentrations of protein (D). Intensity of ERK1/2 protein levels was measured using Quantity One software (Bio-Rad), and total ERK1/2 and phosphorylated ERK1/2 were normalized by $\beta$-actin and total ERK1/2 values, respectively. All values represent the means $\pm \mathrm{SD}$ of three independent experiments. ${ }^{\star} P<0.05 ;{ }^{* \star} P<0.01$; ns, not significant.

damage (Figure 2C), while at this concentration $\mathrm{LLO}_{\mathrm{N} 478 \mathrm{AV} 479 \mathrm{~A}}$ caused very little cell permeabilization (Figure 2D). When the concentration was increased to $20 \mathrm{nM}$, LLO $_{\mathrm{N} 478 \mathrm{AV} 479 \mathrm{~A}}$ became able to cause significant membrane damage while LLO $_{\text {T515AL516A }}$ was still incapable of causing similar damage (Figure 2E). Next, these recombinant LLO variants at the threshold concentrations of 5 or $20 \mathrm{nM}$ were used to determine their effects on ERK1/2 phosphorylation during incubation with Caco- 2 cells. As expected, only wild-type LLO could significantly induce ERK1/2 phosphorylation at the low concentration ( $5 \mathrm{nM})$
(Figure 2F), but by increasing the concentration to $20 \mathrm{nM}$, LLO $_{\text {N478AV479A }}$ began able to activate ERK1/2 phosphorylation as efficiently as wild-type LLO (Figure 2G). However, the LLO $_{\text {T515AL516A }}$ remained incapable of inducing this cellular response regardless of the concentrations used (Figure 2G). A threonine-leucine amino acid pair is conserved in most CDCs and mediates direct binding of these toxins to cholesterol (31). Data obtained here confirmed that the corresponding amino acid pair (Thr515/Leu516) is required for the pore-formation activity of LLO and the consequent LLO-induced ERK1/2 
$$
\text { A }
$$

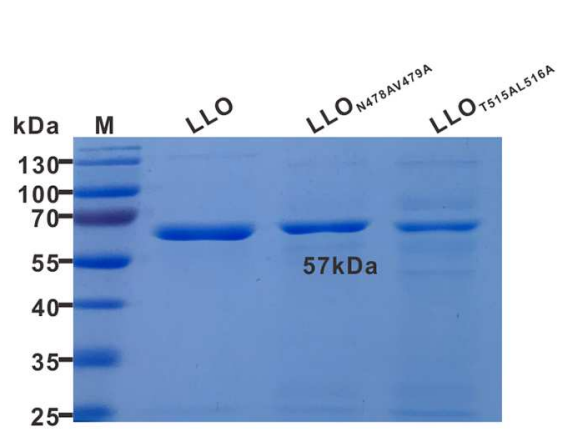

B
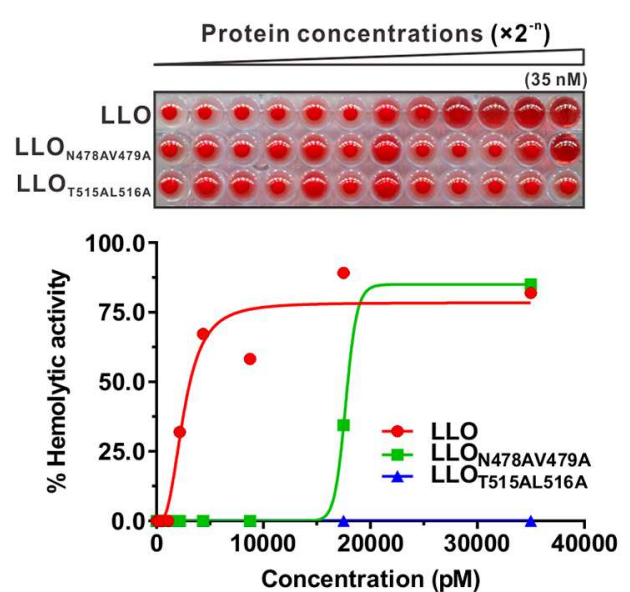

C Various concentrations of LLO
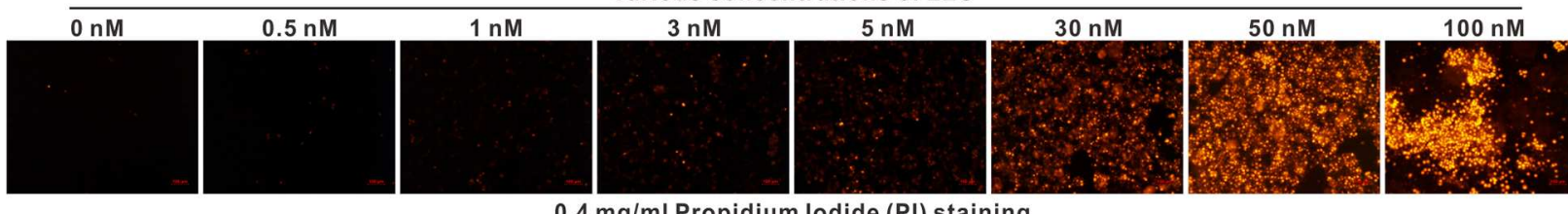

$0.4 \mathrm{mg} / \mathrm{ml}$ Propidium lodide (PI) staining

D

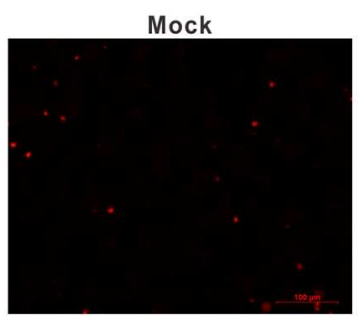

$\mathrm{LLO}_{\mathrm{N} 478 \mathrm{Av} 479 \mathrm{~A}}(5 \mathrm{nM})$

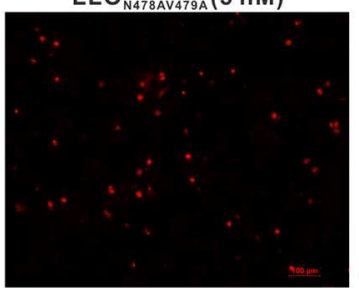

$\mathbf{F}$

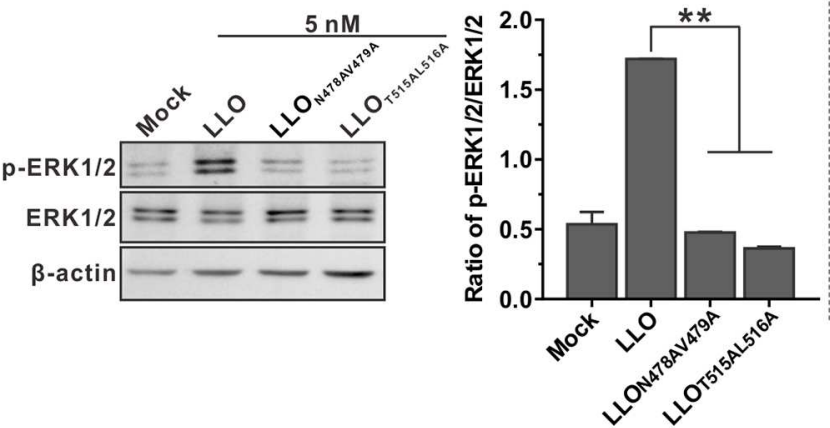

E

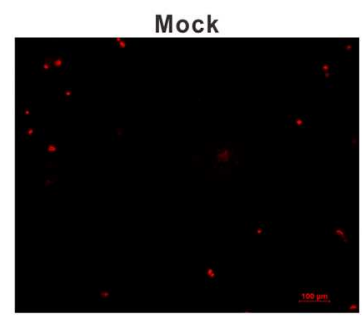

$\mathrm{LLO}_{\mathrm{N} 478 \mathrm{AV} 479 \mathrm{~A}}(20 \mathrm{nM})$

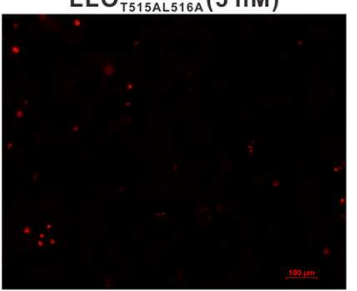

LLO (20 nM)

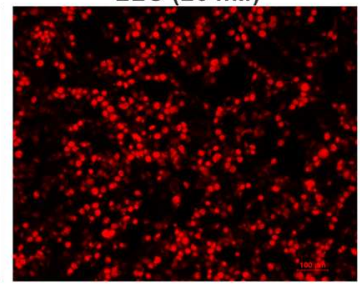

$\mathrm{LLO}_{\mathrm{T} 515 \mathrm{LL} 516 \mathrm{~A}}(20 \mathrm{nM})$

G

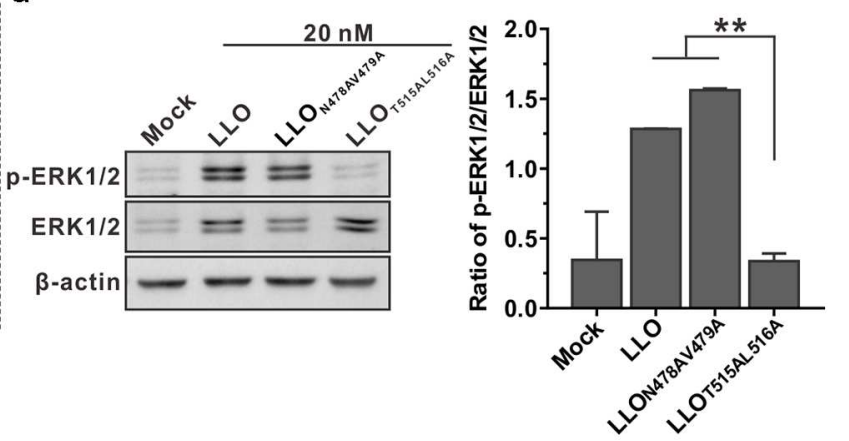

FIGURE 2 | Pore-forming activity is required for LLO-triggered ERK1/2 phosphorylation in Caco-2 cells. (A,B) Purification of the recombinant LLO and its variants (LLOT515AL516A and LLO ${ }_{\text {N478AV479A }}$ ) expressed in E. coli (A) and the hemolytic activity of these proteins at various concentrations (0-35 nM) (B). Erythrocytes incubated 
FIGURE 2 | with 1\% Triton X-100 or PBS served to determine the maximum (100\%) and minimum (0\%) hemolytic activity, respectively. (C-E) Membrane integrity of Caco-2 cells treated with various concentrations of wild-type LLO (C) and treated with LLO variants (LLOT515AL516A and LLON478AV479A) at 5 nM (D) and 20 nM. (E) Cells were treated with sub-lytic and lytic concentrations of recombinant LLO and membrane integrity was assessed by labeling with $0.4 \mathrm{mg} / \mathrm{ml}$ propidium iodide. $\mathbf{( F , G ) ~ E R K 1 / 2 ~ p h o s p h o r y l a t i o n ~ i n ~ C a c o - 2 ~ c e l l s ~ t r e a t e d ~ w i t h ~ L L O ~ o r ~ i t s ~ v a r i a n t s ~ ( L L O T 5 1 5 A L 5 1 6 A ~ a n d ~ L L O N 4 7 8 A V 4 7 9 A ) ~ a t ~ t h e ~ s u b - I y t i c ~ c o n c e n t r a t i o n ~ ( 5 ~ n M ) ~ ( F ) ~ o r ~ a t ~ t h e ~ l y t i c ~}$ concentration $(20 \mathrm{nM}) \mathbf{( G )}$. Values in $\mathbf{( B , F , G ) ~ r e p r e s e n t ~ t h e ~ m e a n ~} \pm \mathrm{SD}$ of three independent experiments. ${ }^{\star \star} P<0.01$; ns, not significant.

activation. Collectively, these findings clearly suggested an important role of the permeable activity in LLO-mediated ERK1/2 phosphorylation.

\section{L. monocytogenes Expressing Inactive LLO Are Unable to Activate ERK1/2 Phosphorylation}

Having established that recombinant $\operatorname{LLO}_{\mathrm{N} 478 \mathrm{AV} 479 \mathrm{~A}}$ and LLO $_{\text {T515AL516A }}$ exhibited different induction effects on ERK1/2 phosphorylation, the L. monocytogenes $\Delta$ hly mutant was complemented with wild-type LLO, LLO N478AV479A or $\mathrm{LLO}_{\mathrm{T} 515 \mathrm{AL} 516 \mathrm{~A}}$ under the natural hly promoter using the Listeria integrative plasmid, pIMK2. As shown by western blotting (Figure 3A), the three complemented strains, $\mathrm{C} \Delta h l y, \mathrm{C} \Delta h l_{\mathrm{N} 478 \mathrm{AV} 479 \mathrm{~A}}$, and $\mathrm{C} \Delta h l_{\mathrm{T} 515 \mathrm{AL} 516 \mathrm{~A}}$, were capable of expressing and secreting LLO or its mutant forms in comparable amounts to the wild-type in the culture supernatant, suggesting that these amino acid substitutions did not affect bacterial LLO synthesis and secretion. The mutations were also confirmed to have no effect on bacterial growth in vitro (Figure 3B). Importantly, hemolytic activity recorded in the secreted supernatant of the mutant $\mathrm{C} \Delta h l y$ with continuous dilution was comparable to that of the wild-type strain, whereas the mutant $\mathrm{C} \Delta h l_{\mathrm{T} 515 \mathrm{AL} 516 \mathrm{~A}}$ did not exhibit any detectable hemolytic activity even in the undiluted stock supernatant, similar to the $\Delta h l y$ mutant. The $\mathrm{C} \Delta h y_{\mathrm{N} 478 \mathrm{AV} 479 \mathrm{~A}}$ strain retained no more than $60 \%$ wild-type hemolytic activity in the secreted supernatant at the initial dilution (Figure 3C). These results were further confirmed by membrane permeabilization assay on Caco-2 cells using PI staining (Figure 3D). Secreted and cytoplasmic proteins isolated from the above mutant strains were then used to investigate their effect on ERK1/2 phosphorylation in Caco-2 cells. The secreted and cytoplasmic LLO from wild-type and complemented strain C $\Delta$ hly could obviously activate phosphorylation of ERK1/2, while the corresponding protein sample from the $\mathrm{C} \Delta h l_{\mathrm{T} 515 \mathrm{AL} 516 \mathrm{~A}}$ mutant as well as the $\Delta$ hly completely failed to induce such a response (Figures 3E,F). However, the secreted and cytoplasmic proteins from the mutant $\mathrm{C} \Delta h h_{\mathrm{N} 478 \mathrm{AV} 479 \mathrm{~A}}$ were able to induce strong phosphorylation of ERK1/2 under the same conditions (Figures 3E,F), consisting with the findings obtained with the recombinant LLO variants. Taken together, although L. monocytogenes expressing $\mathrm{LLO}_{\mathrm{N} 478 \mathrm{AV} 479 \mathrm{~A}}$ retained incomplete hemolytic activity, it was sufficient for this bacterium to trigger ERK1/2 activation. Therefore, we can conclude that LLOinduced phosphorylation of ERK1/2 lies on the pore-forming activity of LLO that is tightly controlled during bacterial intracellular infection.

\section{LLO-Induced ERK1/2 Phosphorylation Is Independent of the PEST-Like Sequence but Can Be Blocked by Exogenous Cholesterol}

The common property of all thiol-activated toxins is that preincubation with low amounts of exogenous cholesterol inhibits hemolytic activity as well as cytolysis of eukaryotic cells (32). This prompted us to investigate the effect of cholesterol-pretreated LLO on activation of ERK1/2 phosphorylation. As determined above, LLO at a concentration of $5 \mathrm{nM}$ was sufficient to induce complete lysis of erythrocytes and ERK1/2 phosphorylation of epithelial cells. A low concentration of $1.3 \mu \mathrm{M}$ cholesterol was sufficient to completely inhibit erythrocyte hemolysis when LLO was incubated with cholesterol before the assay (Figure 4A). This finding was further validated by the membrane permeabilization assay on Caco-2 cells using the PI staining method (Figure 4B). In addition, incubation of Caco-2 cells with LLO pretreated with varying amounts of cholesterol indicated that LLO-induced phosphorylation of ERK1/2 could be inhibited by the presence of small amounts of cholesterol, with the inhibitory effect becoming more significant as the concentration of cholesterol increased (Figure 4C). Although previous studies have documented that pretreatment of LLO with cholesterol inhibits hemolytic activity but does not interfere with the initial binding step of LLO to natural membranes $(32,33)$, we demonstrated that inhibition of ERK1/2 phosphorylation by pre-incubation of LLO with cholesterol was definitely due to loss of cytolytic activity but our data do not rule out an important role for cholesterol in the binding of LLO to the cell membrane. Moreover, LLO contains a unique $\mathrm{N}$-terminal amino acid sequence that is absent in other CDCs, previously referred to as the PEST-like sequence (30). Removal of the PEST-like sequence had very minor effects on LLO pore-forming activity (Figure 4D) and consequently did not affect the unique properties of LLO-mediated ERK1/2 phosphorylation (Figure 4E). Collectively, these data led to the conclusion that LLO-triggered phosphorylation of ERK1/2 is independent of the PEST-like sequence of LLO but can be blocked by addition of exogenous cholesterol.

\section{Listeria-Induced Phosphorylation of ERK1/2 Correlates With Intracellular Infection}

Listeriolysin $O$ plays an essential role in the escape of L. monocytogenes from the phagosome during cell-to-cell spreading. The LLO mutants with varying effects on induction of ERK1/2 activation were investigated for their ability to establish intracellular infection. Firstly, the capability of these LLO mutants to spread from cell to cell was examined by measuring the diameter of plaques formed in L929 fibroblast monolayers. 
A

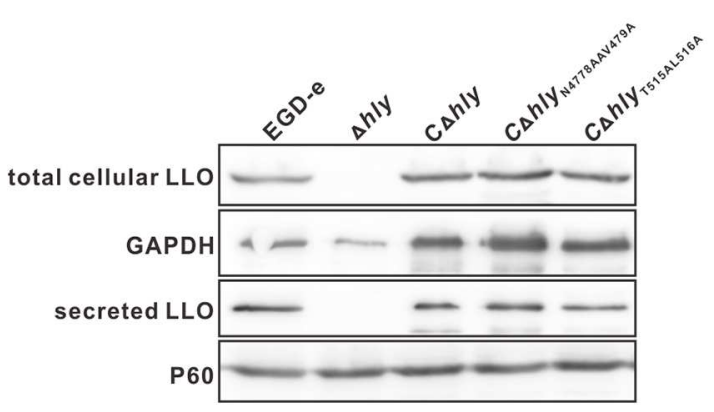

C

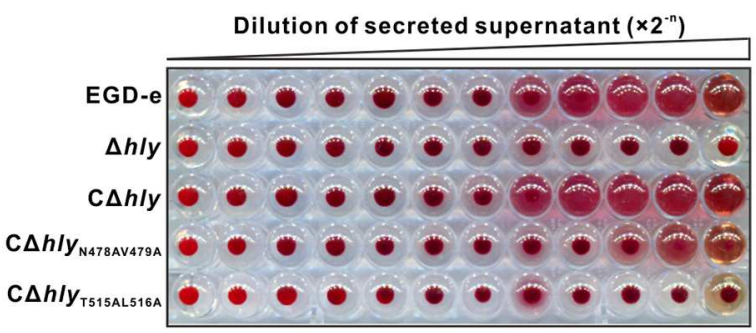

D
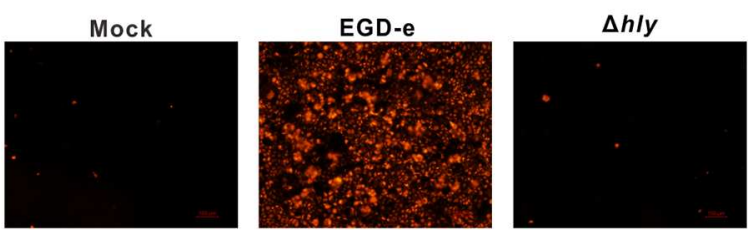

B
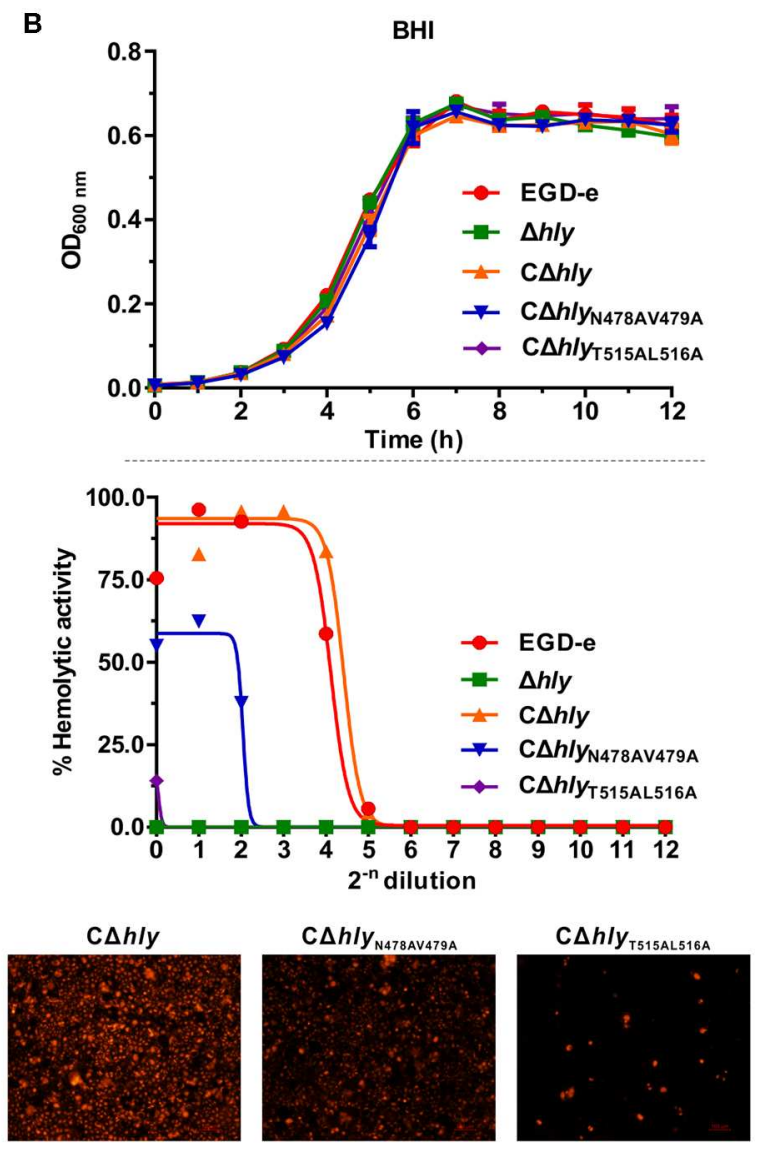

E

Secreted proteins
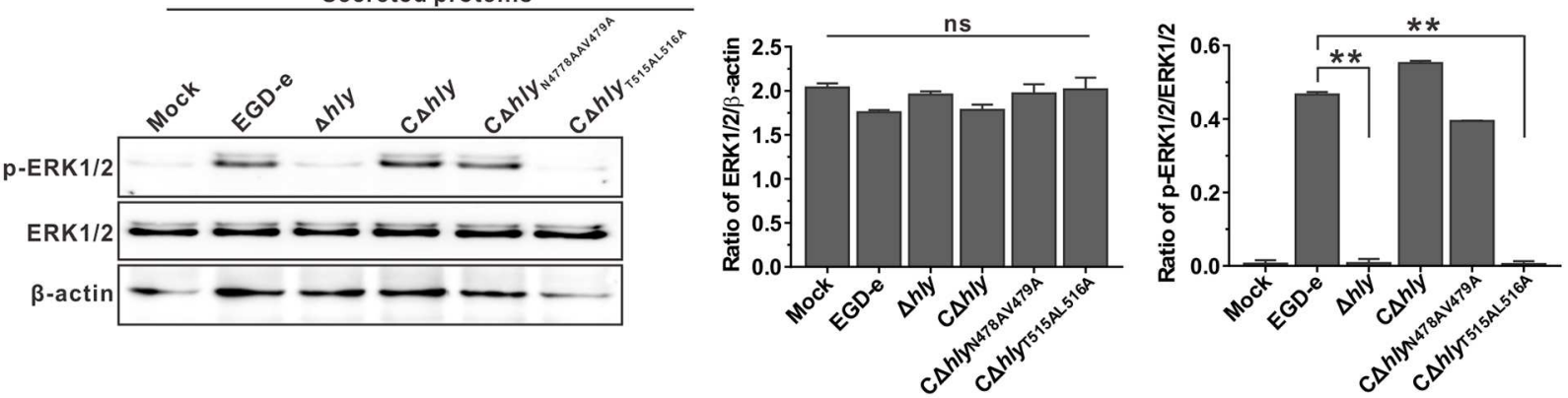

$\mathbf{F}$

Cytoplasm proteins
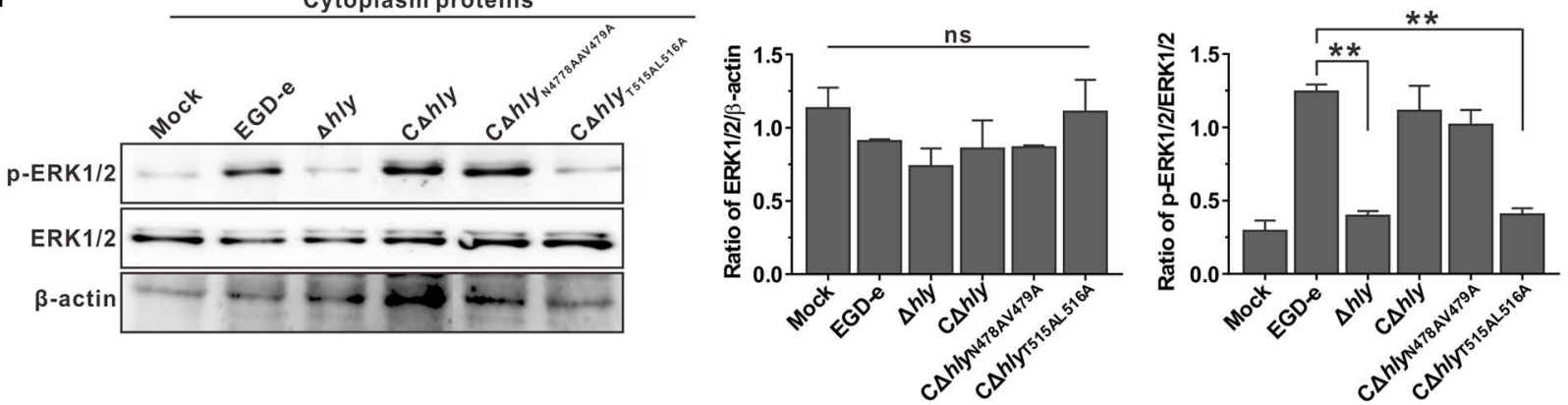

FIGURE 3 | L. monocytogenes expressing inactive LLO were unable to activate ERK1/2 phosphorylation. (A,B) Secreted and cellular LLO detected by western

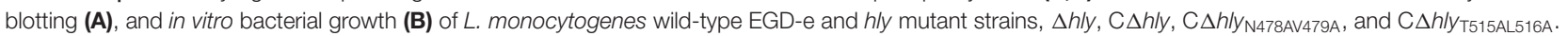


FIGURE 3 | (C) Hemolytic activity of secreted LLO from the culture supernatants of L. monocytogenes WT strain EGD-e and $h l y$ mutant strains, $\Delta$ hly, C $\Delta$ hly,

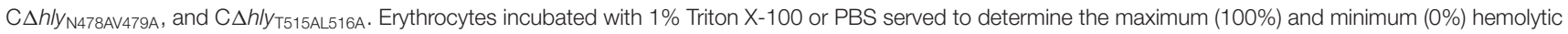
activity, respectively. (D) Membrane integrity of Caco-2 cells treated with bacterial secreted supernatant. Cells were treated with secreted proteins from

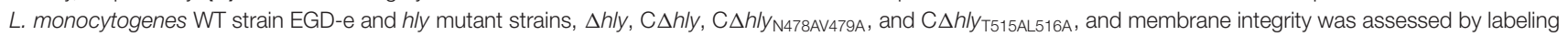
with $0.4 \mathrm{mg} / \mathrm{ml}$ propidium iodide. (E,F) Effects of secreted (E) and cytoplasmic (F) proteins from L. monocytogenes WT strain EGD-e and $h l y$ mutant strains, $\Delta h l y$,

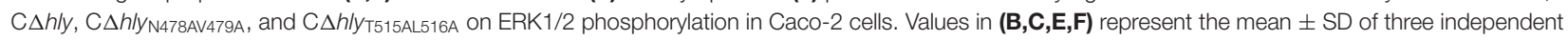
experiments. ${ }^{* \star} P<0.01$; ns, not significant.

Consistent with our previous findings, the partially hemolytic strain $\mathrm{C} \Delta h y_{\mathrm{N} 478 \mathrm{AV} 479 \mathrm{~A}}$ exhibited considerable spreading efficiency compared with the C $\Delta h l y$, although not fully restored to the wild-type level. However, the size of plaques formed by $\mathrm{C} \Delta h h_{\mathrm{T} 515 \mathrm{AL} 516 \mathrm{~A}}$ was significantly smaller than those resulting from infection with the other three strains, suggesting that the two cholesterol-binding sites were crucial to the spreading ability of L. monocytogenes (Figure 5A). In addition, C $\Delta h l_{y_{\mathrm{T}} 515 \mathrm{AL} 516 \mathrm{~A}}$ was significantly impaired in its ability to grow intracellularly in murine-derived macrophages RAW264.7, but grew far better than the LLO-deleted avirulent $\Delta h l y$ strain that was unable to grow (Figure 5B). However, the $\mathrm{C} \Delta h h_{\mathrm{N}_{\mathrm{N}} 78 \mathrm{AV} 479 \mathrm{~A}}$ grew well within macrophages, with comparable efficiency to that of the $\mathrm{C} \Delta h l y$ or wild-type. To directly monitor the cytotoxicity of these LLO mutants, the release of a host cytosolic enzyme, lactate dehydrogenase (LDH), into the tissue culture medium from infected J774 macrophages was detected. At early time points ( 2 and $4 \mathrm{~h}$ ) during infection with any of these strains, very little $\mathrm{LDH}$ was detected either in the presence or absence of gentamicin. At $6 \mathrm{~h}$ post-infection, the amount of $\mathrm{LDH}$ released from all the infected cells, except for the avirulent $\Delta h l y$ strain, increased dramatically, especially in the absence of gentamicin. Surprisingly, the non-hemolytic strain C $\Delta h l y_{\mathrm{T} 515 \mathrm{AL}} 516 \mathrm{~A}$ exhibited a comparable amount of $\mathrm{LDH}$ to the hemolytic strains (Figure 5C), demonstrating that L. monocytogenes expressing LLO $_{\text {T515AL516A }}$ lacks hemolytic activity but exhibits wildtypelevel cytotoxicity to host cell membranes. Moreover, the number of colony-forming units (CFU) of bacteria recovered from the spleens and livers of infected mice after 24 and $48 \mathrm{~h}$ of infection was markedly lower for the strains C $\Delta h l_{y_{\mathrm{N} 478 \mathrm{AV} 479 \mathrm{~A}}(2-3 \text { orders }}$ of magnitude) and $\mathrm{C} \Delta h l_{\mathrm{T} 515 \mathrm{AL} 516 \mathrm{~A}}(3-5$ orders of magnitude) compared with wild-type or the strain expressing wild-type LLO (Figure 5D). This indicated that the two LLO mutants were severely attenuated for virulence, and that mice infected with these mutants exhibited significantly lower bacterial burdens compared with mice infected with the wild-type strain. Combined with the different effects of these LLO mutants on ERK1/2 phosphorylation, we suggest that ERK1/2 signaling triggered by L. monocytogenes infection tightly correlates with the capacity of this bacteria to replicate within host cells.

\section{DISCUSSION}

The pore-forming toxin LLO is the only CDC produced by an intracellular pathogen and is a major virulence factor of L. monocytogenes involved in several stages of the intracellular lifecycle of the bacterium. Following internalization of L. monocytogenes into host cells, LLO disrupts the internalization vacuole, enabling the bacterium to replicate into the host cell cytosol (6). LLO is continuously produced during the intracellular infection of $L$. monocytogenes, while several processes limit its toxicity to survive better inside the host cells. Tightly controlled restriction of the activity of LLO in the internalization vacuole therefore appears to be important for Listeria infection. Various mechanisms responsible for restricting the activity of LLO within the host cell cytoplasm have been investigated, such as its $\mathrm{pH}$ sensitivity, ubiquitylation and proteasomal degradation (11). LLO is a potent signaling molecule, triggering important host cell responses via formation of a large pore complex that allows ions and small molecules to diffuse across the plasma membrane during host infection by the pathogen (9). In the present study, MAPK ERK1/2 phosphorylation in human epithelial Caco-2 cells was strongly triggered by infection with L. monocytogenes. This process is highly dependent on the membrane permeabilization activity of listeriolysin $\mathrm{O}$. The activation effect of LLO on ERK1/2 phosphorylation was concentration-dependent, and a very low concentration of $\sim 5 \mathrm{nM}$ was sufficient to trigger this cellular response. The process could be completely inhibited by cholesterol, which blocks the membrane perforation ability of LLO. Moreover, site-directed mutagenesis of the key amino acids of LLO responsible for partial or complete abolishment of hemolytic activity resulted in different degrees of loss in the capability of LLO to induce ERK1/2 phosphorylation. Overall, these data demonstrated that L. monocytogenes exploits the distinctive characteristics of LLO to finely manipulate the MAPK ERK1/2 signaling pathway during intracellular infection.

Tang et al. originally identified bacterial infection as the stimulus for L. monocytogenes-induced tyrosine phosphorylation of the MAP kinases in HeLa cells (13). In addition, these researchers revealed LLO was the inducing agent by showing that cell-free supernatants from bacteria grown in BHI media were capable of inducing tyrosine phosphorylation (13). Subsequently, (14) confirmed that L. monocytogenes infection of HeLa cells enhanced activity of the Raf kinase, phosphorylation of MEK1, and phosphorylation of the two MAP kinases ERK1 and ERK2, which was most likely mediated by the action of LLO. MAPK activation by $L$. monocytogenes infection was also observed in endothelial cells. In human umbilical vein endothelial cells (HUVECs), phosphorylation of both ERK1/2 and p38, but not JNK, was detected following Listeria infection (22). In addition, infection with L. monocytogenes caused activation of the MAPKs ERK1/2 and p38 in HIBCPP cells, and such response required the Listeria virulence factors internalins A and B (22). However, detailed correlation between the unique properties of LLO and 
A

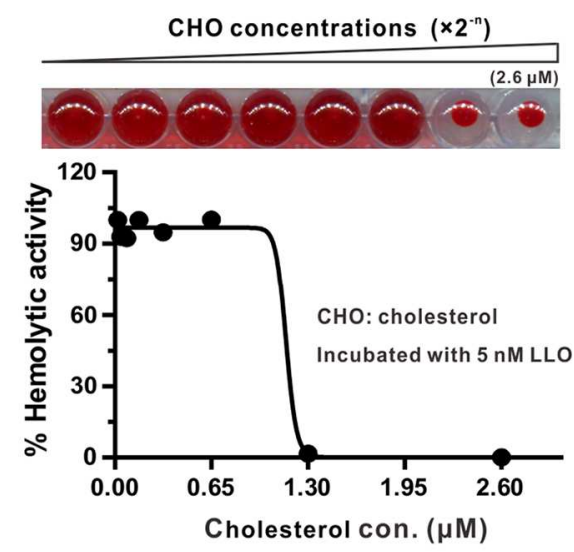

c

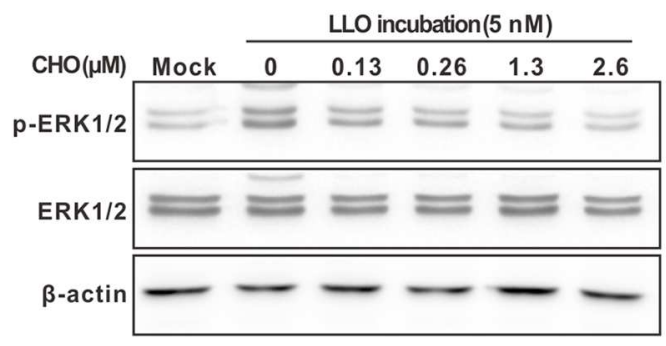

D

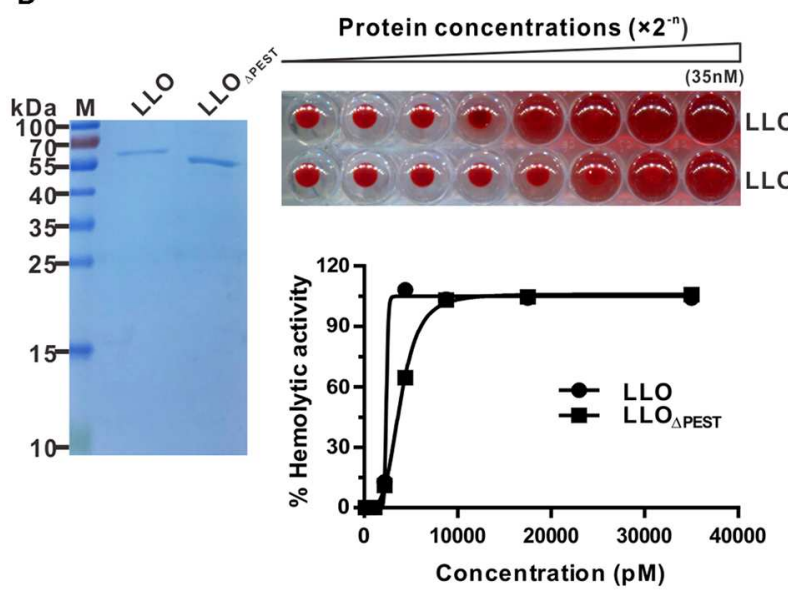

B
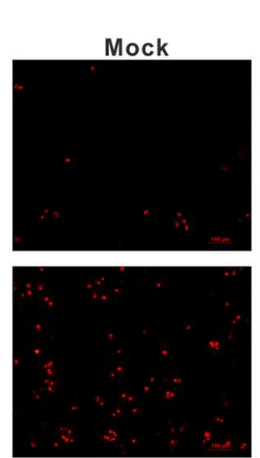

$5 \mathrm{nM}$ LLO

$0.26 \mu \mathrm{M} \mathrm{CHO}$
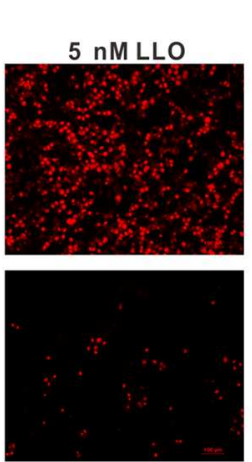

5 nM LLO

$1.3 \mu \mathrm{M} \mathrm{CHO}$
$5 \mathrm{nM}$ LLO

$0.13 \mu \mathrm{M}$ CHO
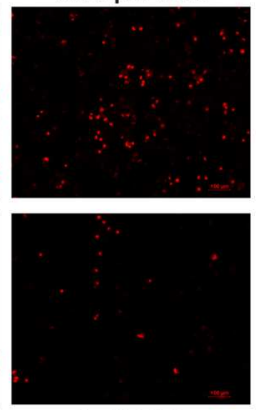

$5 \mathrm{nM}$ LLO

$2.6 \mu \mathrm{M} \mathrm{CHO}$
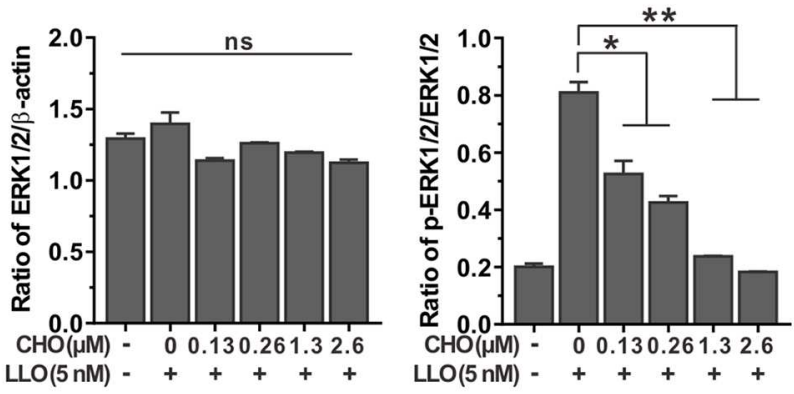

E

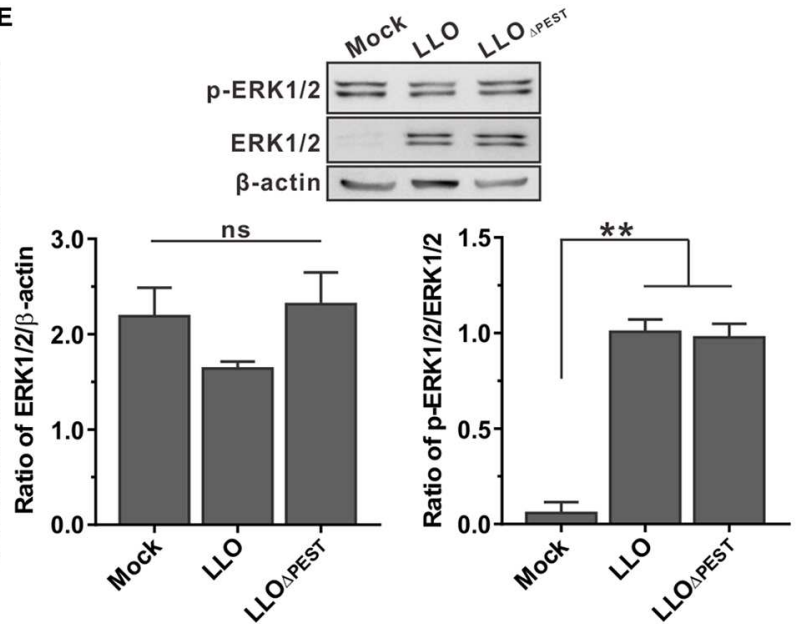

FIGURE 4 | LLO-induced phosphorylation of ERK1/2 is independent of the PEST-like sequence but can be blocked by exogenous cholesterol. (A) Inhibitory effects of cholesterol on hemolytic activity of purified recombinant LLO. Purified LLO at a cytolytic concentration of $5 \mathrm{nM}$ was pre-incubated with different concentrations of cholesterol $(0-2.6 \mu \mathrm{M})$ and hemolytic activity was assessed by lysis of the erythrocytes. (B) Membrane integrity of Caco-2 cells treated with purified LLO and cholesterol. Cells were treated with $5 \mathrm{nM}$ recombinant LLO that had been pre-incubated with varying amounts of cholesterol $(0-2.6 \mu \mathrm{M})$, and the membrane integrity was assessed by labeling with $0.4 \mathrm{mg} / \mathrm{ml}$ propidium iodide. (C) Effects of cholesterol on LLO-induced ERK1/2 phosphorylation in Caco-2 cells. Intensity of total and phosphorylated ERK1/2 protein levels was measured using Quantity One software and normalized with the $\beta$-actin value. (D) Hemolytic activity of purified LLO or its variant LLO $\triangle$ PEST at various concentrations $(0-35 \mathrm{nM}$ ). Erythrocytes incubated with $1 \%$ Triton X-100 or PBS served to determine the maximum (100\%) and minimum $(0 \%)$ hemolytic activity, respectively. (E) Roles of the PEST-like sequence in LLO-induced ERK1/2 phosphorylation in Caco-2 cells. Values in (A,C,D,E) represent the mean \pm SD of three independent experiments. ${ }^{*} P<0.05$; ${ }^{\star} P<0.01$; ns, not significant.

its effects on MAPK activation needs further clarification. In this study, activation of the JNK by L. monocytogenes was also not observed in either of the analyzed settings. This is consistent with the findings of Dinner and co-workers on HIBCPP cells, but is in contrast to the observations of Tang et al. in HeLa cells where JNK could also be activated by $L$. monocytogenes infection $(15,22)$. However, the MAPK p38 could be activated by L. monocytogenes, and this was also LLO-dependent (data not shown). 


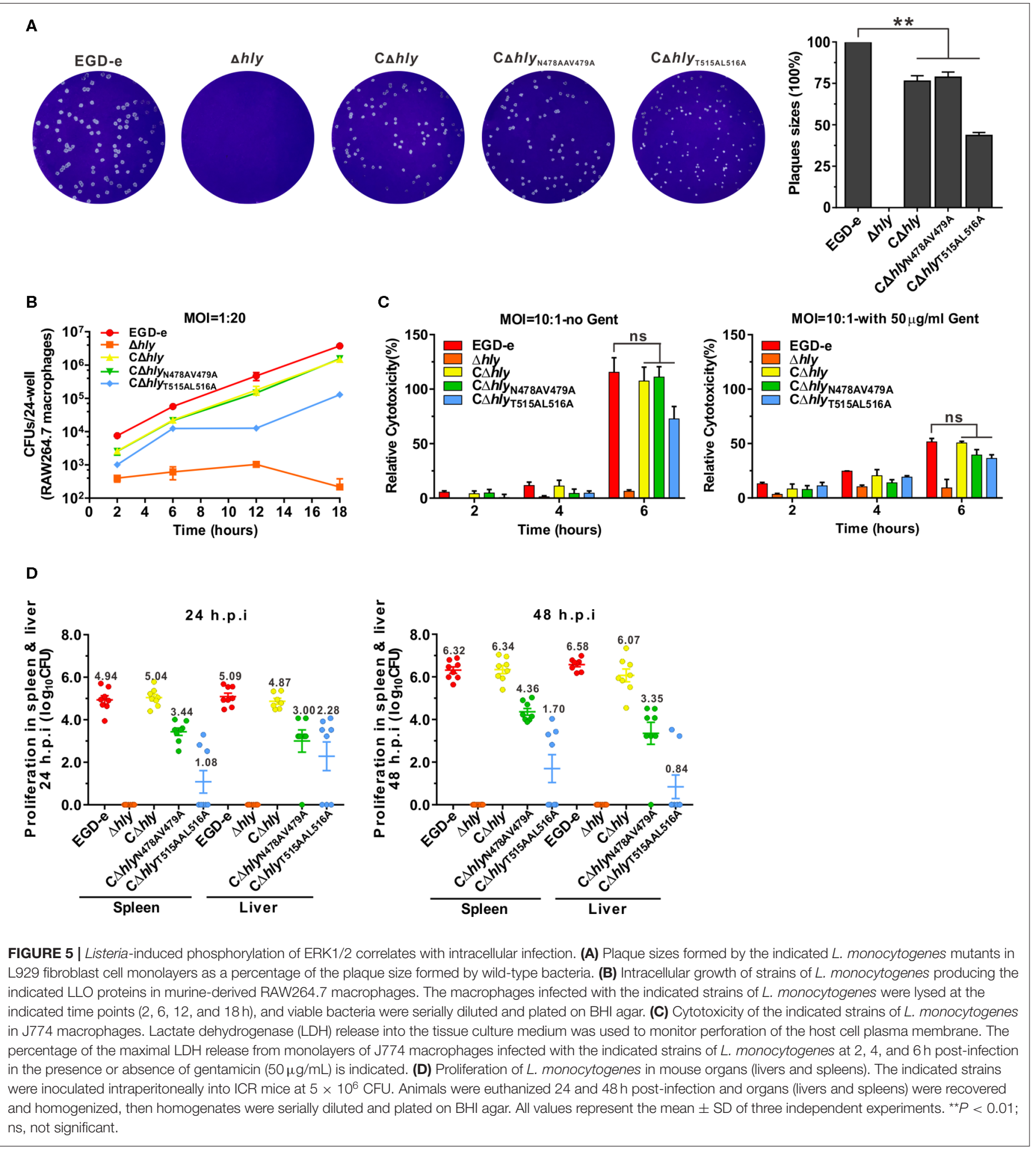

LLO secreted by L. monocytogenes perforates the host cell plasma membrane and rapidly induces a rise in intracellular $\mathrm{Ca}^{2+}$ and an efflux of $\mathrm{K}^{+}$, which have been tightly linked to activation of many signaling pathways. Calcium and calmodulin $(\mathrm{CaM})$ are able to modulate activation of the MAPK pathways, including the Ras/Raf/MEK/ERK signaling pathway, and elevated concentrations of calcium can either activate or, less frequently, inhibit the ERK cascade (34-36). This study, in combination with the existing literature, illustrates the complexity of the cellular responses to LLO and how little is understood about the processes. To our knowledge, cholesterol is the only known cell membrane receptor for LLO and plays an 
essential role in initiating the structural transitions required for pore formation $(37,38)$. CDCs use cholesterol as their membrane receptor and contribute to the pathogenesis of many Grampositive bacterial pathogens (39). Membranes that lack or are significantly depleted of cholesterol are not susceptible to the pore-forming activity of these toxins (40). A remarkably simple structure composed of a threonine-leucine pair of the CDCs functions as the cholesterol-recognition motif and is extremely important for initiating the cholesterol-dependent interaction of CDCs with membranes (31). Here, the corresponding amino acid pair (Thr515-Leu516) was confirmed to be required for LLO binding to cholesterol and subsequent pore formation, enabling LLO to trigger ERK1/2 phosphorylation. Mutants lacking LLO or expressing non-toxic LLO (LLO T515AL516A) revealed that a functional LLO was essential for activation of ERK1/2 in Caco-2 cells. More importantly, our previously identified LLO mutant $\left(\mathrm{LLO}_{\mathrm{N} 478 \mathrm{AV} 479 \mathrm{~A}}\right)$ was unable to lyse erythrocytes within a certain concentration range $(<\sim 15 \mathrm{nM})$, while becoming fully hemolytic at concentrations $>20 \mathrm{nM}$. This change in cytolytic activity was neatly illustrated by the effect

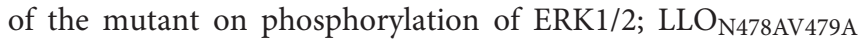
was incapable of inducing ERK1/2 phosphorylation at a low concentration of $5 \mathrm{nM}$, but the impaired ability could be fully restored by increasing the protein concentration to $20 \mathrm{nM}$. In addition, infection of human epithelial cells by L. monocytogenes synthesizing LLO $_{\mathrm{N} 478 \mathrm{AV} 479 \mathrm{~A}}$ efficiently triggered ERK1/2 signaling. We have previously demonstrated that L. monocytogenes expressing LLO $_{\mathrm{N} 478 \mathrm{AV} 479 \mathrm{~A}}$ was highly attenuated but still capable of growing intracellularly in macrophages and spreading cell-to-cell. Moreover, cytotoxicity of this mutant was as low as the wild-type strain (4). To date, the underlying mechanism of N478V479 in contributing to the poreforming activity of LLO remains unclear. These two residues locate very close to the CDCs highly conserved undecapeptide (ECTGLAWEWWR), which was originally thought to be critical for cholesterol-mediated membrane recognition, as mutations in it abolished pore formation (41). However, it has recently been demonstrated that the undecapeptide was not directly responsible for cholesterol binding. Instead, a threonine-leucine pair in the C-terminal part of the protein was important (31). In fact, the conserved undecapeptide was shown to be a key structural element that allows the correct conformation of the cholesterol-binding motif (42), and the Trp-491 and Trp-492 within the motif have an important role linked to cathepsin-D in Listeria triggered innate immunity $(43,44)$. However, according to our previous study, the N478V479 play an important role in regulating the activity of LLO to minimize harm to host cells and thus establish a successful infection for this pathogen. Based on this, we therefore proposed a model suggesting that the moderate cytotoxic activity of LLO is essential for induction of MAPK ERK1/2 phosphorylation during host infection.

While pore-forming toxins allow pathogens to access the host cytosol, their activity must be tightly controlled and compartmentalized to avoid killing the host cells. The PESTlike sequence providing LLO with its uniqueness contributes to the pathogenesis of $L$. monocytogenes by making the LLO a phagosome-specific cytolysin with minimized cytotoxicity (5).
The Portnoy group have shown that deletion of this sequence from LLO does not affect its pore-forming activity, but it does result in an avirulent phenotype. However, they showed that the PEST-like sequence appears to control the production of LLO in the host cell cytoplasm, but it does not promote its degradation (30). We here confirmed that removal of the PEST-like sequence had very minor effects on LLO pore-forming activity (Figure 4D) and consequently did not affect the property of LLO-mediated ERK1/2 phosphorylation (Figure 4E). Together with previously published data, the findings from this study firmly support the view that $L$. monocytogenes has evolved multiple sophisticated mechanisms to minimize harm to host cells by regulating the activity of LLO. To establish a successful infection and achieve maximal virulence, this pathogen must maintain an equilibrium between producing LLO that is cytolytic enough to mediate escape from the vacuole and sufficient to trigger a variety of cellular responses, yet is not overly toxic to infected host cells (45).

The ERK1 and ERK2 pathway has important roles in macrophages, regulating cytokine production via both transcriptional and post-transcriptional mechanisms. ERK1/2 activation downstream of TPL2, the tumor progression locus 2 (MAP3K), has complex effects on inflammatory responses, inducing the production of TNF, IL-1 $\beta$ and IL-10 following Toll-like receptors (TLR) stimulation, but negatively regulating the production of IL-12, IFN- $\beta$ and iNOS (46). Considering the importance of MAPK signaling pathways in regulating immune responses, it is not surprising that many bacterial pathogens have developed sophisticated mechanisms to directly modulate MAPK activation to propagate infection $(24,26)$. One mechanism used by pathogens to modulate MAPK signaling is to interfere with the phosphorylation of MAPK cascades. The virulence of Mycobacterium tuberculosis is inversely related to its ability to activate MAPK signaling. This correlation has been linked to altered expression of the acetyltransferase, enhanced intracellular survival protein (Eis) by acetylating amino terminal lysine residues in the MAPK-docking domain of DUSP16 (47). Yersinia spp. employ the type III secretion system effector protein YopJ to inhibit MAPK by acetylating key residues in the activation loops of MAP kinase kinases (MKKs), which prevents their phosphorylation and consequently blocks the activation of MAPKs (48). Two other bacteria with type III secretion systems, Salmonella enterica and Vibrio parahaemolyticus, also block MAPK activation using acetylases to prevent MKK activation $(49,50)$. Collectively, as we reviewed previous studies on the modulation of MAPK signaling by bacterial pathogens, most of the pathogens were found to have developed mechanisms to directly inhibit MAPK activation for their own gain (24). However, one exception is the pathogen Salmonella enterica serotype Typhimurium (S. Typhimurium) that uses the type III secretion effector SteC to promote actin cytoskeleton reorganization by activating a signaling pathway involving the MAP kinases MEK and ERK, thus contributing to controlling intracellular replication of this pathogen. The rate of intracellular growth of Salmonella appears to be a tightly controlled process involving a balance between the activity of replication-promoting and replication-restraining virulence proteins, and restraining 
bacterial proliferation during infection is also therefore very important for Salmonella virulence (51).

Interestingly, for L. monocytogenes, activation or inactivation of MAPK pathway signaling by L. monocytogenes infection of different host cell types plays a critical role in bacterial invasion and intracellular growth in host cells $(13,15,22,26)$. We suggest that L. monocytogenes has evolved sophisticated mechanisms to flexibly modulate host cell signaling under various infection conditions for its own gain. Moreover, previous studies have shown that the inflammasome was activated by $L$. monocytogenes during infection, and some researchers suggested that caspase-1 activation was LLO-dependent, and such activation of the inflammasome was mediated by the pore-formation activity of LLO on the plasma membrane (52). Although the mechanism employed by LLO to modulate MAPK signaling during L. monocytogenes infection remains elusive, based on these studies we speculate that the pore-forming activity of LLO plays a dominant role in linking LLO-mediated MAPK signaling and host immunity modulation.

In this study, LLO permeabilization activity on the host cell membrane is demonstrated as critical for activating L. monocytogenes infection-induced ERK1/2 phosphorylation, and adding the purified LLO alone at a very low cytotoxic concentration is sufficient to induce this cellular response. The PEST-like sequence is not required for LLO-mediated ERK1/2 phosphorylation during infection, while mutations in the cholesterol-binding motif of LLO render this cytolysin incapable of activating MAPK signaling. Our study generates new insights toward understanding the mechanisms employed by LLO that allow Listeria to trigger a wide range of host cell responses during infection.

\section{REFERENCES}

1. Pizarro-Cerda J, Cossart P. Listeria monocytogenes: cell biology of invasion and intracellular growth. Microbiol Spectr. (2018) 6. doi: 10.1128/microbiolspec.GPP3-0013-2018

2. Radoshevich L, Cossart P. Listeria monocytogenes: towards a complete picture of its physiology and pathogenesis. Nat Rev Microbiol. (2018) 16:32-46. doi: 10.1038/nrmicro.2017.126

3. Rolhion N, Cossart P. How the study of Listeria monocytogenes has led to new concepts in biology. Future Microbiol. (2017) 12:621-38. doi: $10.2217 /$ fmb-2016-0221

4. Cheng C, Jiang L, Ma T, Wang H, Han X, Sun J, et al. Carboxyl-terminal residues $\mathrm{N} 478$ and V479 required for the cytolytic activity of Listeriolysin O play a critical role in Listeria monocytogenes pathogenicity. Front Immunol. (2017) 8:1439. doi: 10.3389/fimmu.2017.01439

5. Chen C, Nguyen BN, Mitchell G, Margolis SR, Ma D, Portnoy DA. The Listeriolysin O PEST-like sequence Co-opts AP-2-mediated endocytosis to prevent plasma membrane damage during listeria infection. Cell Host Microbe. (2018) 23:786-95.e785. doi: 10.1016/j.chom.2018.05.006

6. Nguyen BN, Peterson BN, Portnoy DA. Listeriolysin O: a phagosome-specific cytolysin revisited. Cell Microbiol. (2019) 21:e12988. doi: 10.1111/cmi.12988

7. Glomski IJ, Decatur AL, Portnoy DA. Listeria monocytogenes mutants that fail to compartmentalize listerolysin $\mathrm{O}$ activity are cytotoxic, avirulent, and unable to evade host extracellular defenses. Infect Immun. (2003) 71:6754-65. doi: 10.1128/IAI.71.12.6754-6765.2003

8. Hamon MA, Ribet D, Stavru F, Cossart P. Listeriolysin O: the Swiss army knife of Listeria. Trends Microbiol. (2012) 20:360-8. doi: 10.1016/j.tim.2012.04.006

\section{DATA AVAILABILITY STATEMENT}

The datasets generated for this study are available on request to the corresponding author.

\section{ETHICS STATEMENT}

The animal study was reviewed and approved by Institutional Animal Care and Use Committee of Science Technology Department of Zhejiang Province (Permit Number: SYXK-2018-0010).

\section{AUTHOR CONTRIBUTIONS}

CC, JS, and HS conceived and designed the experiments and wrote the paper. CC, JS, HY, TM, HZ, CG, ZC, and XZ performed the experiments and analyzed the data. CC, JS, ZC, and HS acquired the funds. All authors contributed to the review of the manuscript.

\section{FUNDING}

This work was funded by National Natural Science Foundation of China (31872620 for CC, 31770040 and 31972648 for HS, 31602062 for JS), Natural Science Foundation of Zhejiang Province (LZ19C180001 for HS, LQ19C180002 for JS, and LQ20C010001 for ZC), and the Xinmiao Talent Plan of Zhejiang Province (2018R412042). The funders had no role in study design, data collection and analysis, decision to publish, or preparation of the manuscript.

9. Seveau S. Multifaceted activity of listeriolysin O, the cholesterol-dependent cytolysin of Listeria monocytogenes. Subcell Biochem. (2014) 80:161-95. doi: 10.1007/978-94-017-8881-6_9

10. Koster S, van Pee K, Hudel M, Leustik M, Rhinow D, Kuhlbrandt W, et al. Crystal structure of listeriolysin O reveals molecular details of oligomerization and pore formation. Nat Commun. (2014) 5:3690. doi: 10.1038/ncomms4690

11. Schnupf P, Portnoy DA. Listeriolysin O: a phagosome-specific lysin. Microbes Infect. (2007) 9:1176-87. doi: 10.1016/j.micinf.2007.05.005

12. Gonzalez MR, Bischofberger M, Freche B, Ho S, Parton RG, van der Goot FG. Pore-forming toxins induce multiple cellular responses promoting survival. Cell Microbiol. (2011) 13:1026-43. doi: 10.1111/j.1462-5822.2011.01600.x

13. Tang P, Rosenshine I, Cossart P, Finlay BB. Listeriolysin O activates mitogenactivated protein kinase in eucaryotic cells. Infect Immun. (1996) 64:2359-61. doi: 10.1128/IAI.64.6.2359-2361.1996

14. Weiglein I, Goebel W, Troppmair J, Rapp UR, Demuth A, Kuhn M. Listeria monocytogenes infection of HeLa cells results in listeriolysin O-mediated transient activation of the Raf-MEK-MAP kinase pathway. FEMS Microbiol Lett. (1997) 148:189-95. doi: 10.1111/j.1574-6968.1997.tb10287.x

15. Tang P, Sutherland CL, Gold MR, Finlay BB. Listeria monocytogenes invasion of epithelial cells requires the MEK-1/ERK-2 mitogenactivated protein kinase pathway. Infect Immun. (1998) 66:1106-12. doi: 10.1128/IAI.66.3.1106-1112.1998

16. Ribet D, Hamon M, Gouin E, Nahori MA, Impens F, Neyret-Kahn H, et al. Listeria monocytogenes impairs SUMOylation for efficient infection. Nature. (2010) 464:1192-5. doi: 10.1038/nature08963

17. Gekara NO, Westphal K, Ma B, Rohde M, Groebe L, Weiss S. The multiple mechanisms of $\mathrm{Ca} 2+$ signalling by listeriolysin $\mathrm{O}$, the cholesterol-dependent 
cytolysin of Listeria monocytogenes. Cell Microbiol. (2007) 9:2008-21. doi: $10.1111 / j .1462-5822.2007 .00932 . x$

18. Stavru F, Bouillaud F, Sartori A, Ricquier D, Cossart P. Listeria monocytogenes transiently alters mitochondrial dynamics during infection. Proc Natl Acad Sci USA. (2011) 108:3612-7. doi: 10.1073/pnas.1100126108

19. Meixenberger K, Pache F, Eitel J, Schmeck B, Hippenstiel S, Slevogt H, et al. Listeria monocytogenes-infected human peripheral blood mononuclear cells produce IL-1beta, depending on listeriolysin O and NLRP3. J Immunol. (2010) 184:922-30. doi: 10.4049/jimmunol.0901346

20. Hamon MA, Batsche E, Regnault B, Tham TN, Seveau S, Muchardt C, et al. Histone modifications induced by a family of bacterial toxins. Proc Natl Acad Sci USA. (2007) 104:13467-72. doi: 10.1073/pnas.0702729104

21. Krachler AM, Woolery AR, Orth K. Manipulation of kinase signaling by bacterial pathogens. J Cell Biol. (2011) 195:1083-92. doi: $10.1083 /$ jcb.201107132

22. Dinner S, Kaltschmidt J, Stump-Guthier C, Hetjens S, Ishikawa $\mathrm{H}$, Tenenbaum $\mathrm{T}$, et al. Mitogen-activated protein kinases are required for effective infection of human choroid plexus epithelial cells by Listeria monocytogenes. Microbes Infect. (2017) 19:18-33. doi: 10.1016/j.micinf.2016.09.003

23. Plotnikov A, Zehorai E, Procaccia S, Seger R. The MAPK cascades: signaling components, nuclear roles and mechanisms of nuclear translocation. Biochim Biophys Acta. (2011) 1813:1619-33. doi: 10.1016/j.bbamcr.2010.12.012

24. Arthur JS, Ley SC. Mitogen-activated protein kinases in innate immunity. Nat Rev Immunol. (2013) 13:679-92. doi: 10.1038/nri3495

25. Chalenko Y, Kalinin E, Marchenkov V, Sysolyatina E, Surin A, Sobyanin K, et al. Phylogenetically defined isoforms of Listeria monocytogenes invasion factor InlB differently activate intracellular signaling pathways and interact with the receptor gC1q-R. Int J Mol Sci. 20:4138. doi: 10.3390/ijms20174138

26. Hashino M, Tachibana M, Nishida T, Hara H, Tsuchiya K, Mitsuyama M, et al. Inactivation of the MAPK signaling pathway by Listeria monocytogenes infection promotes trophoblast giant cell death. Front Microbiol. (2015) 6:1145. doi: 10.3389/fmicb.2015.01145

27. Camilli A, Tilney LG, Portnoy DA. Dual roles of plcA in Listeria monocytogenes pathogenesis. Mol Microbiol. (1993) 8:143-57. doi: 10.1111/j.1365-2958.1993.tb01211.x

28. Xayarath B, Alonzo F III, Freitag NE. Identification of a peptide-pheromone that enhances Listeria monocytogenes escape from host cell vacuoles. PLoS Pathog. (2015) 11:e1004707. doi: 10.1371/journal.ppat.1004707

29. Cheng C, Dong Z, Han X, Wang H, Jiang L, Sun J, et al. Thioredoxin $\mathrm{A}$ is essential for motility and contributes to host infection of Listeria monocytogenes via redox interactions. Front Cell Infect Microbiol. (2017) 7:287. doi: $10.3389 /$ fcimb.2017.00287

30. Decatur AL, Portnoy DA. A PEST-like sequence in listeriolysin O essential for Listeria monocytogenes pathogenicity. Science. (2000) 290:992-5. doi: $10.1126 /$ science.290.5493.992

31. Farrand AJ, LaChapelle S, Hotze EM, Johnson AE, Tweten RK. Only two amino acids are essential for cytolytic toxin recognition of cholesterol at the membrane surface. Proc Natl Acad Sci USA. (2010) 107:4341-6. doi: 10.1073/pnas.0911581107

32. Jacobs T, Darji A, Frahm N, Rohde M, Wehland J, Chakraborty $\mathrm{T}$, et al. Listeriolysin $\mathrm{O}$ : cholesterol inhibits cytolysis but not binding to cellular membranes. Mol Microbiol. (1998) 28:1081-9. doi: $10.1046 / j .1365-2958.1998 .00858 . x$

33. Lety MA, Frehel C, Dubail I, Beretti JL, Kayal S, Berche P, et al. Identification of a PEST-like motif in listeriolysin O required for phagosomal escape and for virulence in Listeria monocytogenes. Mol Microbiol. (2001) 39:1124-39. doi: $10.1111 / j .1365-2958.2001 .02281 . x$

34. Cullen PJ, Lockyer PJ. Integration of calcium and Ras signalling. Nat Rev Mol Cell Biol. (2002) 3:339-48. doi: 10.1038/nrm808

35. Chuderland D, Seger R. Calcium regulates ERK signaling by modulating its protein-protein interactions. Commun Integr Biol. (2008) 1:4-5. doi: 10.4161/cib.1.1.6107

36. White CD, Sacks DB. Regulation of MAP kinase signaling by calcium. Methods Mol Biol. (2010) 661:151-65. doi: 10.1007/978-1-60761-795-2 9

37. Ramachandran R, Tweten RK, Johnson AE. Membrane-dependent conformational changes initiate cholesterol-dependent cytolysin oligomerization and intersubunit beta-strand alignment. Nat Struct Mol Biol. (2004) 11:697-705. doi: 10.1038/nsmb793
38. Soltani CE, Hotze EM, Johnson AE, Tweten RK. Specific proteinmembrane contacts are required for prepore and pore assembly by a cholesterol-dependent cytolysin. J Biol Chem. (2007) 282:15709-16. doi: 10.1074/jbc.M701173200

39. Tweten RK. Cholesterol-dependent cytolysins, a family of versatile pore-forming toxins. Infect Immun. (2005) 73:6199-209. doi: 10.1128/IAI.73.10.6199-6209.2005

40. Howard JG, Wallace KR, Wright GP. The inhibitory effects of cholesterol and related sterols on haemolysis by streptolysin O. Br J Exp Pathol. (1953) 34:17480.

41. Michel E, Reich KA, Favier R, Berche P, Cossart P. Attenuated mutants of the intracellular bacterium Listeria monocytogenes obtained by single amino acid substitutions in listeriolysin O. Mol Microbiol. (1990) 4:2167-78. doi: 10.1111/j.1365-2958.1990.tb00578.x

42. Dowd KJ, Farrand AJ, Tweten RK. The cholesterol-dependent cytolysin signature motif: a critical element in the allosteric pathway that couples membrane binding to pore assembly. PLoS Pathog. (2012) 8:e1002787. doi: 10.1371/annotation/750e7055-3a67-44ac-88e1-673d017a15c7

43. Tsuchiya K, Kawamura I, Takahashi A, Nomura T, Kohda C, Mitsuyama M. Listeriolysin O-induced membrane permeation mediates persistent interleukin-6 production in Caco-2 cells during Listeria monocytogenes infection in vitro. Infect Immun. (2005) 73:3869-77. doi: 10.1128/IAI.73.7.3869-3877.2005

44. Carrasco-Marin E, Madrazo-Toca F, de los Toyos JR, Cacho-Alonso E, Tobes $\mathrm{R}$, Pareja E, et al. The innate immunity role of cathepsin-D is linked to Trp491 and Trp-492 residues of listeriolysin O. Mol Microbiol. (2009) 72:668-82. doi: $10.1111 / j .1365-2958.2009 .06673 . x$

45. Glomski IJ, Gedde MM, Tsang AW, Swanson JA, Portnoy DA. The Listeria monocytogenes hemolysin has an acidic $\mathrm{pH}$ optimum to compartmentalize activity and prevent damage to infected host cells. J Cell Biol. (2002) 156:102938. doi: $10.1083 /$ jcb. 200201081

46. Dumitru CD, Ceci JD, Tsatsanis C, Kontoyiannis D, Stamatakis K, Lin $\mathrm{JH}$, et al. TNF-alpha induction by LPS is regulated posttranscriptionally via a Tpl2/ERK-dependent pathway. Cell. (2000) 103:1071-83. doi: 10.1016/S0092-8674(00)00210-5

47. Kim KH, An DR, Song J, Yoon JY, Kim HS, Yoon HJ, et al. Mycobacterium tuberculosis Eis protein initiates suppression of host immune responses by acetylation of DUSP16/MKP-7. Proc Natl Acad Sci USA. (2012) 109:7729-34. doi: 10.1073/pnas.1120251109

48. Mukherjee S, Keitany G, Li Y, Wang Y, Ball HL, Goldsmith EJ, et al. Yersinia YopJ acetylates and inhibits kinase activation by blocking phosphorylation. Science. (2006) 312:1211-4. doi: 10.1126/science.1126867

49. Trosky JE, Li Y, Mukherjee S, Keitany G, Ball H, Orth K. VopA inhibits ATP binding by acetylating the catalytic loop of MAPK kinases. J Biol Chem. (2007) 282:34299-305. doi: 10.1074/jbc.M706970200

50. Jones RM, Wu H, Wentworth C, Luo L, Collier-Hyams L, Neish AS. Salmonella AvrA coordinates suppression of host immune and apoptotic defenses via JNK pathway blockade. Cell Host Microbe. (2008) 3:233-44. doi: 10.1016/j.chom.2008.02.016

51. Odendall C, Rolhion N, Forster A, Poh J, Lamont DJ, Liu M, et al. The Salmonella kinase SteC targets the MAP kinase MEK to regulate the host actin cytoskeleton. Cell Host Microbe. (2012) 12:657-68. doi: 10.1016/j.chom.2012.09.011

52. Hamon MA, Cossart P. K+ efflux is required for histone $\mathrm{H} 3$ dephosphorylation by Listeria monocytogenes listeriolysin $\mathrm{O}$ and other pore-forming toxins. Infect Immun. (2011) 79:2839-46. doi: 10.1128/IAI.01243-10

Conflict of Interest: The authors declare that the research was conducted in the absence of any commercial or financial relationships that could be construed as a potential conflict of interest.

Copyright $\odot 2020$ Cheng, Sun, Yu, Ma, Guan, Zeng, Zhang, Chen and Song. This is an open-access article distributed under the terms of the Creative Commons Attribution License (CC BY). The use, distribution or reproduction in other forums is permitted, provided the original author(s) and the copyright owner(s) are credited and that the original publication in this journal is cited, in accordance with accepted academic practice. No use, distribution or reproduction is permitted which does not comply with these terms. 